\title{
26th Annual Meeting of the International Society of Blood Purification (ISBP)
}

September 20-22, 2008, Brijuni, Croatia

\section{Abstracts}

Guest Editors

Robert Zietse, Rotterdam

Stanley Shaldon, Monaco

\section{Contents}

Symposium I

25th Anniversary of the IL-1 Hypothesis:

Cytokines as Mediators of ESRD

Symposium II

Geriatric Dialysis

Symposium III

Predicting Clinical Features for Blood Purification:

From in vitro Assessment to Clinical Trials

ISBP Award Lecture

Invited Lecture

Oral Presentations

Abstracts 01-021

Poster Presentations

Abstracts P22-P46

ISBP Trustees Best Abstract Awards 


\section{Symposium I \\ 25th Anniversary of the IL-1 Hypothesis: Cytokines as Mediators of ESRD}

\section{Interleukin-1 Beta and the Treatment of Auto-Inflammatory Disease}

Charles A. Dinarello

Department of Medicine, University of Colorado Health Sciences Center, Denver, Colorado, USA

Chronic inflammatory diseases are either "autoimmune" or "autoinflammatory". In autoimmune diseases, the T-cell is dysfunctional and TNF and IFN are the cytokines to block. The "Auto-inflammatory Diseases" encompass several local and systemic diseases due to monocyte dysfunction, each responsive to blocking interleukin-beta (IL-1 $\beta$ ). "The Auto-inflammatory Diseases" include type 2 diabetes and gout. The best example is Familial Mediterranean Fever since the manifestations of this disease include fever, inflamed serosal and synovial tissues, biochemical markers of systemic inflammation and hematological responses of leukocytosis. Some of the syndromes have mutations in the protein "cryopyrin" and are called "cryopyrinopathies"; however, identical biochemical, hematological and clinical disease is observed in patients without mutations. What is common link? The common link is dysregulation of the tight control over the processing and secretion of IL- $1 \beta$ from the activated monocyte. The processing and secretion of IL- $1 \beta$ is a function of the IL-1 $\beta$ /caspase-1 "inflammasome", a complex of intracellular proteins that results in the secretion of IL-1 $\beta$. Despite the highly consistent clinical response to blocking the activity of IL-1 $\beta$ in these diseases, circulating IL-1 $\beta$ is difficult to detect. The Auto-inflammatory Diseases are examples in cytokine biology that only specific blockade reveals the role of a cytokine in a disease process. Several trials of anti-IL-1 $\beta$ are currently underway.

\section{Cytokines in Endstage Renal Diseases}

\section{Gerhard Lonnemann}

Centre of Nephrology and Hemodialysis, Langenhagen, Germany

In 1983 the interleukin hypothesis was proposed providing the missing link between parameters of bio(in)compatibility of the extracorporeal blood circuit and clinical problems in chronic hemodialysis patients. Subsequent studies proved the concept that adverse reactions to complement-activating cellulosic dialyzer membranes, dialysis hypotension during acetate-dialysis as well as pyrogenic reactions due to microbiologically contaminated dialysate involve the stimulation of circulating mononuclear cells (PBMC) to produce proinflammatory peptides called endogenous pyrogens and after purification and cloning are renamed cytokines such as interleukin-1 (IL-1), IL-6 and tumor necrosis factor alpha. Stimulation of cytokine production three times a week maintains a state of chronic inflammation with increased plasma levels of C-reactive protein (CRP), subfebrile body temperatures, catabolic waste of muscle mass, low albumin levels and also accelerated atherosclerosis, the MIA syndrome (malnutrition, inflammation, atherosclerosis). Technical improvements such as the replacement of sodium acetate by bicarbonate, sterile filters in the dialysate circuit to reduce bacterial growth and pyrogens (e.g. endotoxins) in dialysis fluids, and the introduction of pyrogen-adsorbing non-complement-activating synthetic dialyzer membranes have all been shown to reduce cytokine-induction and CRP levels in ESRD patients. Proinflammatory cytokines are counteracted by anti-inflammatory cytokines such as IL-10. There is a polymorphism in the IL10 gene. In the ESRD population, high IL-10 producers have been identified who have low CRP levels and a lower risk of cardiovascular mortality. ESRD per se is a two-face inflammatory disease with multiple stimuli of proinflammatory cytokines in PBMC on one hand and impaired T-cell function on the other. T-cell activation depends on adequate function of antigen-presenting cells (APC) with the paracrine production of cytokines such as IL-2, IL-4, IL-12, IL-18 and Interferon gamma (IFN $\gamma$ ). IFN $\gamma$ production is suppressed in ESRD patients leading to an impaired T-helper 1 response and NKcell function. Retrospective analyses showed that both, chronic inflammation as well as impaired T-cell function are associated with increased mortality in ESRD patients. Impaired APC function and IFN $\gamma$ production in ESRD patients are, at least in part, due to high levels of beta2-microglobulin and can be improved using high-flux hemodialysis. Conclusion: High-flux hemodialysis, biocompatible synthetic dialyzer membranes and ultrafiltered bicarbonate-buffered dialysis fluid are recommended to prevent the induction of proinflammatory cytokines in the extracorporeal circuit, to remove costimulatory factors such as beta $2-\mathrm{m}$ and advanced glycation endproducts (mainly by adsorption) and to improve lymphocyte function. It is anticipated that biocompatible high-flux hemodialysis will improve survival of ESRD patients.

\section{Sodium Binding to Matrix Proteins: Implications for Cardiovascular Diseases}

\section{Jens Titze \\ University of Erlangen, Erlangen, Germany}

The relationship between body $\mathrm{Na}^{+}$and fluid retention is taught to medical students as a done deal. The paradigm is that $\mathrm{Na}^{+}$is

\footnotetext{
KARGER

Fax +41613061234

E-Mail karger@karger.ch

www.karger.com

(C) 2008 S. Karger AG, Basel

0253-5068/08/0265-0430\$24.50/0

Accessible online at: www.karger.com/bpu
} 
restricted mainly to the extracellular fluid and $\mathrm{K}^{+}$to the intracellular space, where both ions act to hold water and thereby control the extracellular and intracellular fluid volume by their osmotic activity. $\mathrm{Na}^{+}$accumulation thus inevitably leads to commensurate water retention. Given the assumption that plasma and interstitial $\mathrm{Na}^{+}$concentrations are very similar; the constancy of the extracellular volume is the task of the kidneys, which control the serum $\mathrm{Na}^{+}$content and are hence believed to control the interstitial and thereby body $\mathrm{Na}^{+}$content almost exclusively. More recent data from balance studies in humans have questioned this traditional view, suggesting that large amounts of $\mathrm{Na}^{+}$can be accumulated without accompanying water retention by osmotically inactive $\mathrm{Na}^{+}$retention, or by osmotically neutral $\mathrm{Na}^{+} / \mathrm{K}^{+}$exchange. Besides the control of the body $\mathrm{Na}^{+}$ content by the kidneys, redistribution of body electrolytes hence provides an extrarenal regulatory alternative in the maintenance of body fluid volume and blood pressure control. Most recent experimental evidence suggests that $\mathrm{Na}^{+}$retention in the skin interstitium is characterized not only by $\mathrm{Na}^{+}$storage, but also by a remarkable degree of interstitial hypertonicity. The physiologic response of the body to this interstitial $\mathrm{Na}^{+}$excess includes increases in the interstitial glycosaminoglycan content and sulfatation, and thereby an increase in the polyanionic character of the extracellular matrix which presumably binds $\mathrm{Na}^{+}$in an osmotically inactive form. Furthermore, $\mathrm{Na}^{+}-$ induced interstitial hypertonicity is a physiological signal for interstitial macrophages to secrete vascular endothelial growth factor $\mathrm{C}$ (VEGF-C), inducing interstitial lymhangiogenesis. Failure of this macrophage-driven lymphangiogenesis in response to $\mathrm{Na}^{+}$-mediated interstitial hypertonicity results in interstitial $\mathrm{Na}^{+}$overload and hypertension. This finding suggests that macrophages are regulators in interstitial electrolyte homeostasis, and bridges electrolyte intake with inflammatory alterations which may contribute to target-organ damage. In summary, experimental data are not in accord with the currently favoured two-compartment model of interstitial electrolyte and body fluid homeostasis. Instead, recent evidence suggests that the interstitial space functions as an independent $3^{\text {rd }}$ compartment with separate regulatory alternatives to maintain extracellular salt and water balance. Not only the absolute amount of interstitial volume, but also the relationship between interstitial electrolyte and volume content, namely interstitial tonicity, is a critical local component for extrarenal regulation of interstitial volume and blood pressure homeostasis. Serum $\mathrm{Na}^{+}$levels do not reflect the dramatic changes in interstitial $\mathrm{Na}^{+}$concentrations. This different view on basic regulatory concepts of the "milieu interieur" may open new research avenues for understanding cellular function in the interstitial space and the pathogenesis of hypertension.

\section{Symposium II Geriatric Dialysis}

\section{Overview of Geriatric Dialysis Patients in Japan}

Tadao Akizawa

Division of Nephrology, Department of Medicine, Showa

University School of Medicine, Tokyo, Japan

At the end of 2007, prevalence of dialysis patients was 275119 (PMP: 2153.2). Mean age of the prevalent patient is 64.9 years old (y.o). Among them, patients above 75 y.o occupies $24 \%$ (male $21.5 \%$, female $27.9 \%$ ), and high prevalence in female depend on the high average life span of female in general population. 296 patients are over than 95y.o. Incidence of dialysis patients on 2007 was 36909 , and mean age was 66.8 y.o. Among them, patients above 75 y.o occupies $31.8 \%$ (male $28.2 \%$, female $38.4 \%$ ), high incidence in female also depends on longer life span. 51 patients over than 95 y.o started dialysis treatment this year. Analyzing the sample patients on 2006, in aged patients (above 75 y.o) male, aging, diabetes, low BMI and serum albumin were significant factors to deteriorate the survival, but these factors also suppress the survival for younger patients. The back ground parameters in aged patients showed shorter dialysis vintage and smaller BW than younger patients without marked difference in $\mathrm{Kt} / \mathrm{V}$, nPCR, inter-dialytic weight gain and serum albumin. Longer dialysis (above 5 hour ) improved the survival and shorter dialysis (below 3.5hr) shorten the survival in whole analysis, but for aged patients longer dialysis did not affect the survival and shorter dialysis still deteriorated the outcome. Geriatric dialysis patient is common and increasing in Japan. Even though ageing per se is an important factor to deteriorate the survival and QOL, but adequate dialysis, nutrition and care may helpful to compensate the poor outcome of the patients.

\section{Frailty and Dependence in Elderly Dialysis Patients}

Giovanni Panzetta

S.C. Nefrologia e Dialisi, Azienda Ospedaliero-

Universitaria di Trieste, Trieste, Italy

A new category of patients aged $>75$ years, namely the elderly, is now being freely admitted to hemodialysis (HD) and this category is becoming predominant. Indeed, patients older than $75 \mathrm{yrs}$ of age currently represent more than $35 \%$ of the population that begins dialysis in most European registries; in our centre at least 30 patients in this age bracket begin dialysis every year, which represent $45 \%$ of the total incident patients. The absence of systematic studies makes this patient category almost indistinguishable from other categories, even though its peculiarity is now becoming evident. At least 30-40\% of individuals in this age bracket are expected to be frail and/or dependent, but 
the incidence of frailty is likely to be higher in the elderly undergoing HD. Due to severe physical and/or mental impairment and often because of strong social hardship, these patients rarely experience clinical stability and are dependent on third parties for their survival. Their care produces complex problems for welfare services and this has proved responsible for modifying the organization of renal care units. These repeated patient admissions to hospital are filling nephrology facilities, and the dialysis management requires a much greater use of facilities and staff than normal if compared to average dialysis patients. In 112 elderly patients consecutively admitted to the dialysis program over a period of $10 \mathrm{yrs}$, we identified 35 dependent patients $(31.2 \%)$, even taking into consideration only extreme degrees of infirmity. Dependence proved to be the only clinical parameter associated with survival (mortality at 6 months $23.4 \%$ vs $10.6 \%$, $\mathrm{p}<0,01$; Kaplan-Meyer survival curves: $\mathrm{p}<0.03$ log-rank test), while comorbidities (in particular cardiovascular that usually affect dialysis mortality rates) did not seem to be discriminating risk factors in the elderly. More precisely, with the confirmation of these data through wider case studies, the idea will be reinforced that, also in dialysis, the elderly must be constantly monitored for frailty and dependence, as is the case in any exclusively geriatric field. Indeed, many of the clinical problems of the dialyzed elderly, such as sensory, mental, and functional impairment, are more the result of advanced age per se rather than of uremia or of dialysis. Prevention, as well as a therapeutic approach specifically modelled on these conditions, could help to improve the prognosis of this patient category, which is particularly difficult to deal with and is becoming predominant in dialysis units.

\section{Geriatric Dialysis: Mortality Data and Prognosis. An Overview}

\author{
Michael Germain \\ Western New England Renal and Transplant Associates, \\ Springfield, MA, USA
}

In the USA, the fastest growing incident dialysis cohort is patients $>75$. These patients have extraordinary high 6 and 12-month mortality. While the dialysis population as a whole have had a modest but steady improvement in survival over the past 10 years, the $>75$ patients have a declining 6 month survival. These patients have amongst the highest symptom burden, including severe pain, of any chronic illness, yet there is low hospice utilization, high \% of patients dying in the hospital/ICU, and palliation of symptoms. It is critical to be able to predict short-term survival accurately and communicate this information effectively to the patient and family. This will allow the clinician to help plan effective end of life planning with the patient and family. Since these patients have a worse prognosis that HIV and most cancer patients, effective palliative care and appropriate use of hospice are essential. Algorithm: Accurate prognostic prediction (presentation of a new prognostic tool) Effective communication of prognostic information to patient and family Establish goals of care-advanced directives For patient with a $<6$ month prognosis Aggressive palliative care/effective pain control Physician Order for Life-Sustaining Treatment (POLST) (Do not resuscitate orders) Hospice services Discuss dialysis withdrawal Bereavement program for the family and staff

\section{Dialysis or Not? Considerations for Conservative Management}

Fliss E.M. Murtagh

Department of Palliative Care, Policy and Rehabilitation, King's College London, Weston Education Centre,

London, UK

End-stage renal disease (ESRD) is predominantly a disease of the elderly. With the increasing population age in developed countries, the number of people requiring renal replacement therapy is steadily rising. Increasing age is associated with greater co-morbidity and many patients reaching ESRD have other significant, particularly cardiovascular, pathology. It is generally accepted that older patients with significant co-morbidity do less well on dialysis, but there is little comparative data on either survival or quality of life, including symptoms. This presentation will critically review the evidence on survival and on quality of life, including symptom burden, for patients with stage 5 chronic kidney disease managed conservatively, without dialysis. It will include consideration of what conservative management is, what components of care are required, and which models of care best apply. Original research will be presented comparing survival in dialysis and conservative patients over 75 years, which suggests that, in the setting of managed nephrological care, older patients with significant co-morbidity, particularly ischaemic heart disease, do not gain significant benefit from dialysis treatment. For this group of patients, conservative management is a realistic treatment option. Evidence will also be presented which describes the high symptom burden of these patients and the need to identify interventions which improve patient-centered outcomes, such as reduction in symptom distress and improved quality of life. Recent evidence suggests these patients do not follow a predictable symptom trajectory, but may experience diverse and sometimes fluctuating course of symptoms over time. Models of care need to be developed with the flexibility and responsiveness necessary to meet these symptom and other needs.

\section{Symposium III \\ Predicting Clinical Features for Blood Purification: From in vitro Assessment to Clinical Trials}

\section{Establishing in vitro Models to Study Endothelial Functions}

\author{
C.J. Kirkpatrick, M.I. Hermanns, S. Fuchs, F. Bittinger, \\ R.E. Unger \\ Institute of Pathology, University Hospital, Johannes \\ Gutenberg-University, Mainz, Germany
}

One of the major challenges of in vitro research is the adequate simulation of the in vivo state being studied. Structural heterogeneity of the endothelium has been known for a long time, but it has become 
increasingly apparent during the past decades that there is immense functional diversity. Many of the disease pathomechanisms of interest take place in the microcirculation, including inflammation, tumour extravasation and disturbed healing processes. An adequate in vitro model should if possible involve endothelial cells (EC) of human origin, used in early passage and with the requirement of maintaining a functional phenotype. Occasionally, permanent EC lines are developed, which also need to be tested for stable functional parameters [1]. Diseases such as sepsis or therapies such as blood purification, which involve a major systemic component, can exert great influence on pulmonary function. We have established a co-culture model of the human lung involving alveolocytes and human pulmonary microvascular EC (HPMEC), giving a stable barrier function, which can however be reversibly modulated [2]. This barrier is particularly vulnerable to modulation from the endothelial side and offers a model to study acute lung injury during sepsis. Systemic factors also influence healing processes, of which angiogenesis is a central reaction. Various models have been established, including co-cultures with osteoblasts to study bone regeneration [3]. Great interest is now being focussed on circulating endothelial progenitor cells, which can adopt a marked angiogenic phenotype [4] and have considerable therapeutic potential.

\section{References}

1. Unger RE et al. 2002; Microvasc Res 64: 384

2. Hermanns MI et al. 2004; Lab Invest 84: 736

3. Unger RE et al. 2007; Biomaterials 28: 3965

4. Fuchs S et al. 2006; Cell Tissue Res 326: 79

\section{Impact of Sodium on Endothelial Cells \\ Paul W. Sanders \\ Division of Nephrology, University of Alabama at Birmingham, Birmingham, AL, USA}

The traditional focus on resistance vessels in hypertension has expanded in recent years to include study of larger arteries, in part because large epidemiology studies have shown that systolic blood pressure, which is determined by arterial compliance of conduit arteries, predicts the development of end-stage kidney disease and cardiovascular disease and mortality. Animal and human data support an untoward effect of excess dietary salt intake on cardiovascular and renal function and dietary salt reduction and volume reduction rapidly improve carotid artery compliance. To explore the mechanism by which salt generates these adverse effects, my laboratory examines the effects of salt intake on endothelial production of transforming growth factor- $\beta 1$ (TGF- $\beta 1$ ), a fibrogenic growth factor that facilitates matrix protein deposition in the arterial wall, and nitric oxide (NO). The findings have supported the concept that plasticity of the endothelium plays an integral role in altering the expression of important bioactive molecules in response to changes in dietary salt intake and further have suggested a paradigm for intravascular production of TGF- $\beta 1$ in response to dietary salt intake, with the endothelium serving as an important source of TGF- $\beta 1$, along with a central modulating role for NO. The effect is independent of both angiotensin II and systemic blood pressure. Production of TGF- $\beta 1$ in response to changes in salt intake is a function of multiple independent signaling cascades that appear to be initiated by shear forces and include Smad2/3, p38 MAPK, and p42/44 MAPK. Dietary salt intake also facilitates the endothelial production of NO by directly impacting on endothelial NO synthase expression and activity, and NO serves as a countervailing force that mitigates the actions of TGF- $\beta 1$. A central feature of this model is the relationship between TGF- $\beta 1$ and NO and the findings have relevance in disease states that include end-stage kidney disease.

\section{Importance of Volume Control in Patients on Maintenance Hemodialysis Treatment}

Gülay Asci

Department of Internal Medicine, Division of

Nephrology, Ege University School of Medicine, Izmir, Turkey

Cardiovascular diseases are the major cause of death in patients on chronic hemodialysis. Hypertension is present in the majority of the hemodialysis patients and composes a significant risk factor for cardiovascular diseases, including left ventricular hypertrophy, heart failure, and ischemic heart disease. Therapeutic approach to hypertension in most of the dialysis centers is usually based on anti-hypertensive drug regimens even though the usage of anti-hypertensive medication is not effective for reaching optimal blood pressure levels in the majority of these patients. Left ventricular hypertrophy, which is related to hypertension and an important cause for cardiovascular death, is frequently persistent and progressive in dialysis patients. Furthermore, usage of anti-hypertensive drugs cannot prevent progression or provide regression of left ventricular hypertrophy. Only a few centers apply "strict volume strategies", which is mainly based on lowering dry weight by using salt restricted diet and appropriate ultrafiltration until optimal blood pressure is achieved, without prescribing any anti-hypertensive drugs. Unsurprisingly, most of the patients who are treated in dialysis centers where volume control strategies are used for the management of hypertension have normal blood pressure levels along with better survival. Results from several uncontrolled studies including patients on nocturnal hemodialysis or center hemodialysis with longer dialysis sessions suggest that this policy is quite effective for control of hypertension and regression of left ventricular hypertrophy. Moreover, it has been shown that optimal blood pressure control can also be achieved by this therapeutic approach in patients on thrice weekly conventional hemodialysis. In consistent with the results of the uncontrolled trials, in a recent controlled study which compares the effects of two different treatment policies on prevalence of hypertension and left ventricular hypertrophy, it was found that patients treated by anti-hypertensive medication-based approach have significantly higher left ventricular mass index compared with the patients on volume control-based treatment. Frequency of the patients with left ventricular hypertrophy and also hypertension were significantly lower in patients treated with volume-based strategy. In addition, strict volume control strategy was associated with less intradialytic hypotension episodes and better cardiac functions. Achieving normovolemia with support of salt-restricted diet makes possible to reach optimal blood pressure levels in patients receiving conventional hemodialysis therapy. For this purpose it seems to be essential and a reasonable 
choice for the prevention of detrimental cardiovascular effects of hypertension in this population.

\section{ISBP Award Lecture}

\author{
Targeting Ubiquitin Proteasome System \\ Ivan Dikic \\ Institute of Biochemistry, Frankfurt University, \\ Frankfurt/Main, Germany; Mediterranean Institute for Life \\ Sciences (MedILS), Split, Croatia
}

Ubiquitin is a small modifier that labels proteins in a highly specific manner. Like phosphorylation, the modification of proteins with ubiquitin is prevalent in the majority of normal and pathological cellular processes. Initially, ubiquitination was described as the process of tagging proteins for degradation in the proteasome, a giant protein complex responsible for the breakdown of the majority of intracellular proteins. Alterations in the proteasome are associated with several human diseases, such as cardiac dysfunction, cataract formation, neurodegenerative diseases, cachexia and rheumatoid diseases. An inhibitor of the proteasome (Bortezomib) is currently in use as an anti-cancer therapeutic to treat patients suffering from haematological tumours, such as multiple myeloma and relapsed mantle cell lymphoma. The common principles and specific features of recognition of ubiquitinated proteins and their degradation by the proteasome will be discussed. We have recently identified Rpn13 as a novel ubiquitin receptor at the proteasome, which binds to lysine 48-linked ubiquitin chains and also recruits deubiquitinating enzyme Uch37 to the proteasome, thus being able to co-ordinate recognition and disassembly of ubiquitinated substrates at the proteasome. More recently, an increasing number of distinct functions have been assigned to different types of ubiquitin modifications (mono ubiquitin versus ubiquitin chains), e.g. the regulation of protein trafficking, the assembly of protein signalling complexes as well as the activation or inactivation of enzymatic activities. In these processes Ub acts as a signalling component able to trigger molecular events in cells. Ub does so by operating as a reversible and highly versatile regulatory signal for an expanding number of Ub-binding domains (UBD) present in cellular proteins that convey Ub signals into appropriate cellular phenotypes. The common principles and specific features of $\mathrm{Ub}$ and other Ub-like modifiers and their binding domains in the regulation of physiological and patho-physiological processes will be further discussed.

\section{References}

1. Husnjak $\mathrm{K}$ et al. Proteasome subunit Rpn13 is a novel ubiquitin receptor. Nature 2008, 453:481-488.

2. Schreiner $\mathrm{P}$ et al. Ubiquitin docking at the proteasome via a novel $\mathrm{PH}$ domain interaction. Nature 2008, 453:548-552.

3. Hoeller D et al. E3-independent monoubiquitination of ubiquitin-binding proteins. Mol. Cell 2007, 26:891-8.

4. Hoeller D et al. Ubiquitin and ubiquitin-like proteins in cancer pathogenesis. Nature Reviews Cancer 2006, 6:776-88.
5. Bienko $\mathrm{M}$ et al. Novel ubiquitin-binding domains in Y-family polymerases regulate translesion DNA synthesis. Science 2005, 310:1821-4.

\section{Invited Lecture}

\section{Impact of High-Flux Hemodialysis on Clinical Outcomes: Results of Recent Clinical Trials}

\author{
Stefan H. Jacobson \\ Department of Medicine, Division of Nephrology, \\ Danderyd University Hospital, Karolinska Institute, \\ Stockholm, Sweden
}

High-flux dialysis membranes are removing a larger and a broader spectrum of uraemic solutes. There is evidence that high-flux dialysis, compared to low-flow flux dialysis leads to a more efficient reduction of serum B2-microglobulin, a lower incidence of dialysis related amyloidosis, a slower decrease of residual renal function and improvement of lipid profiles. A number of observational and retrospective studies have shown that high-flux dialysis results in a reduction in the risk of death as compared to low-flux dialysis. In one recent study from DOPPS, patients treated with high efficiency hemodiafiltration had the lowest mortality. Post hoc analysis from the 4-D study also showed lower cardiovascular mortality and total mortality in patients treated with high-flux membranes. In the prospective randomized controlled HEMO-study, prevalent dialysis patients were treated with low-flux or high-flux membranes. They reported no difference in total mortality between patients on high-flux membranes compared to low-flux membranes. For patients who had been on dialysis for more than 3.7 years, all cause mortality was lower with high-flux membranes. The primary objective of the European prospective randomized MPO-study was to study survival of incident dialysis patients on bicarbonate hemodialysis treated with either high-flux or low-flux membranes. The focus of the study was to enrol patients at risk, defined as having a serum albu$\min \leq 4 \mathrm{~g} / \mathrm{dl}$. The minimum observation period was three years. The MPO-study showed that survival was significantly better with highflux dialysis for patients with a serum albumin of $\leq 4 \mathrm{~g} / \mathrm{dl}$. Furthermore, mortality was significantly lower with high-flux dialysis membranes for patients with diabetes, irrespective of serum albumin level. In addition, patients treated with high-flux membranes had significantly less increase in B-2 microglobulin during the study. In conclusion, there are retrospective and observational data in favour for a decreased risk of mortality with high-flux hemodialysis membranes. The HEMO-study from the United States, including prevalent dialysis patients, showed however no difference in survival between high-flux and low-flux treated patients. By contrast, in the MPO-study incident European dialysis patients at risk had significantly better survival with high-flux hemodialysis. 


\section{Oral Presentations}

\section{ISBP Trustees Best Abstract Award Endogenous Testosterone and Mortality Due to All-Causes and Cardiovascular Disease in Men Undergoing Hemodialysis}

\author{
J.J. Carrero (presenting), A.R. Qureshi, P. Parini, S. Arver, \\ B. Lindholm, P. Bárány, O. Heimbürger and P. Stenvinkel \\ Divisions of Renal Medicine and Baxter Novum, \\ Karolinska Institutet, Stockholm, Sweden
}

Introduction: Men undergoing hemodialysis (HD) have a very poor prognosis and an elevated risk of premature cardiovascular disease (CVD). Also, more than $50 \%$ of the HD men present testosterone deficiency. In the general population, links between low testosterone concentrations and the risk of future cardiovascular events have recently been suggested. Methods: We performed a prospective population study examining the relationship between endogenous testosterone concentrations and subsequent mortality in a well-characterized cohort of 126 prevalent HD men (median age 63 [inter quartile range 49-73] years, vintage time 26 [14-55] months). Testosterone levels were compared with various inflammatory markers, as well as baseline co-morbidities. All-cause and CVD-related mortality was assessed during a follow-up period of 41 (20-47) months. Results: Independently of age and sexual hormone binding globulin (SHBG), testosterone levels were inversely and strongly linked to inflammatory markers (IL-6 and CRP) as well as to nt-ProBNP levels. Also, patients with a clinical history of CVD presented significantly lower testosterone levels. During follow-up, 65 deaths occurred, $58 \%$ of which due to CVD causes. Men in the lower tertile of testosterone distribution had increased all-cause and CVD mortality (crude hazard ratios [HRs] 2.03 [95\% CI 1.24-3.31] and 3.19 [1.49-6.83], respectively) that persisted after adjustment for age, SHBG, previous CVD, diabetes and inflammation (adjusted HRs 1.65 [0.99-2.76] and 2.66 [1.19-5.93], respectively). Conclusion: In males on $\mathrm{HD}$, testosterone concentrations are inversely related to mortality due to both CVD and all-cause. At the same time, a strong inverse correlation was observed between testosterone and inflammatory markers. Low testosterone concentration may constitute an additional cardiovascular risk factor in CKD men.
02 ISBP Trustees Best Abstract Award

\section{Clinical Significance of the Malnutrition- Inflammation-Atherosclerosis (MIA) Syndrome in the Patients on Maintenance Hemodialysis}

S. Rački (presenting), L. Zaputovic' ${ }^{1}$, Ž. Mavric' ${ }^{1}$, P. Kes, ${ }^{2}$ B. Vujičic'1 , I. Mrakovčić-Šutic'

${ }^{1}$ Department of Nephrology and Dialysis, University Hospital Center Rijeka, ${ }^{2}$ Department of Dialysis,

University Hospital Centre Zagreb, Zagreb,Croatia

Objectives: To evaluate a clinical significance of the Malnutrition-Inflammation-Atherosclerosis (MIA) syndrome as a cardiovascular risk factor in the maintenance hemodialysis patients. Methods: 208 maintenance hemodialysis patients were assessed in the period from June 2005 to June 2007. A total of 168 patients were analyzed. The diagnosis of MIA syndrome was established using the MIA score assessed with appropriate scale and it was positive in 66 patients. Two-year mortality and morbidity were followed according to presence of MIA syndrome. Patients with MIA syndrome were randomized into four groups and treated with atorvastatin, online hemodiafiltration (OL-HDF), Helixone ${ }^{\circledR}$ membrane, and standard hemodialysis. The MIA syndrome parameters were evaluated after follow-up of 12 and 24 months. A statistical analysis was performed using the appropriate tests using the statistical software MedCalc 7,5 (MedCalc, Mariakerke, Belgium). Results: Mean patients age was $63 \pm 13$ years with equal gender distribution. The most common underlying renal disease was chronic glomerulonephritis $(31,0 \%)$. The MIA syndrome was present in $39,3 \%$ of patients. Their mortality was significantly higher $(36,4 \%$ vs. $12,7 \%, p=0,0006)$. Causes of death did not differ according to the presence of MIA syndrome. The most common cause of death was cardiovascular disease $(62,2 \%)$, particularly myocardial infarction $(24,3 \%)$. Basal clinical and laboratory data of the patients with MIA syndrome at the time of randomization were similar. The patients treated with atorvastatin, OL-HDF and Helixone ${ }^{\circledR}$ membrane had better survival than patients treated with standard hemodialysis $(\mathrm{p}=0,0032)$. Independent mortality predictors in the patients with MIA syndrome were not found but MIA score was almost significant $(\mathrm{p}=0,0681)$. Treatment with atorvastatin and OL-HDF significantly reduced serum C-reactive protein levels $(\mathrm{p}=0,0161 ; \mathrm{p}=0,0425)$, and serum interleukin-6 levels $(\mathrm{p}=$ $0,0005 ; \mathrm{p}=0,021)$ after 12 and 24 months, respectively. Treatment with OL-HDF showed beneficial effect on anemia treatment $(\mathrm{p}=0,0049)$ as well as significantly reduced serum triglyceride levels $(\mathrm{p}=0,042)$. Treatment with atorvastatin was also beneficial regarding the influence on the serum triglyceride levels $(p=0,0049)$, and was safe without significant side effects. Conclusion: Atorvastatin, OL-HDF and use of the new Helixone ${ }^{\circledR}$ membrane were beneficial in the treatment of patients with MIA syndrome. 
03

\section{Long-Term ( $\geq 30$ Years) Hemodialysis Survivors in Slovenia}

J. Buturovic'-Ponikvar (presenting)1', R. Ponikvar',

M. Malovrh'1, A. Kandus', M. Benedik', J. Varl',

A. Marn-Pernat', B. Knap ${ }^{1}$, J. Kovač ${ }^{1}$, V. Premru',

Z. Ceglar' ${ }^{2}$ S. Saksida ${ }^{3}$, S. Kapun ${ }^{4}$

${ }^{1}$ Department of Nephrology, University Medical Center

Ljubljana, ${ }^{2}$ Dialysis center, General Hospital Izola, ${ }^{3}$ Dialysis

center, General Hospital Nova Gorica, ${ }^{4}$ Nefrodial Krško,

Slovenia

Objective: To present data on $\geq 30$ years hemodialysis survivors in Slovenia. Methods: Patients that started renal replacement therapy (RRT) in 1978 or earlier were identified from Slovenian RRT Registry. Clinical data on March 2008 are presented. Results: There were 1835 prevalent RRT patients on December 31, 2006 (population of Slovenia is 2 million, prevalence rate $913 \mathrm{pmp}$ ). $69.3 \%$ of them were treated by chronic hemodialysis $(\mathrm{n}=1271,55.2 \%$ men, median age 65 years, range 17-93, 19.2\%-diabetic nephropathy, 24.2\%-diabetics). 33 patients were alive, treated by RRT $\geq 30$ years, $(32 \pm 2.0$, 30-36), 2 treated with kidney transplantation, 15 with hemodialysis and kidney transplantation, and 16/33 by chronic hemodialysis: 7 men and 9 women, aged $62 \pm 12$ years (46-84), duration of hemodialysis $31.6 \pm 1.5$ years $(30-35.5)$. Primary renal disease was glomerulonephritis in 8 , pyelonephritis in 3 , analgesic nephropathy in one, lupus nephritis in one, unknown nephropathy in 3 . None had diabetes. One had 18-month period of functioning cadaveric kidney graft, the other graft that never functioned, one had 12-year period of peritoneal dialysis. Vascular access is AV fistula in 10 patients, PTFE graft in 3 and single-lumen noncuffed catheter, locked with citrate, used as permanent vascular access (for years), in 3 patients. 3/16 patients are treated with 4 times-week, 13/16 by 3 times-week hemodialysis, 4/16 by HDF and $12 / 16$ by bicarbonate hemodialysis. The weekly duration of hemodialysis is $14.0 \pm 2.0$ hours (12-16.5), dry body weight $52.4 \pm 9.6 \mathrm{~kg}(32.5-65 \mathrm{~kg})$, mean blood flow $264 \pm 52 \mathrm{ml} / \mathrm{min}$. Two patients with catheter are dialyzed by single-needle technique. 6/16 patients do not receive epoetin, the mean weekly dose in 10/16 patients receiving epoetin is 4300 units, intravenously. Kidney transplantation status: $8 / 16$ patients refused to be transplanted, 3 are not candidates because of age (and comorbidity) and 5 because of medical contraindications. Conclusions: In Slovenia $33(1.8 \%)$ of prevalent RRT patients were alive on RRT $\geq 30$ years, 16 of them treated by chronic hemodialysis. The longest duration of chronic hemodialysis treatment was 35.5 years.

\section{4}

\section{Characteristics of Dialysis-Related Amyloidosis in Patients on Hemodialysis Therapy for More than $\mathbf{3 0}$ Years}

\author{
S. Otsubo (presenting)', N. Kimata ${ }^{2}$, K. Oshikawa', \\ S. Ueda', H. Sugimoto', M. Mitobe ${ }^{3}, K$. Uchida$^{3}$, \\ K. Otsubo', O. Otsubo ${ }^{1}, K$. Nitta ${ }^{3}$ and T. Akiba ${ }^{2}$ \\ ${ }^{1}$ Sangenjaya Hospital, Tokyo, ${ }^{2}$ Department of Blood \\ Purification, Kidney Center, Tokyo Women's Medical \\ University, Tokyo, ${ }^{3}$ Department of Medicine, Kidney \\ Center, Tokyo Women's Medical University, Tokyo, Japan
}

Objectives: Dialysis-related amyloidosis is one of chronic complications of hemodialysis. We conducted an investigation of dialysisassociated amyloidosis in extremely long-term survivors. Method: Twenty-one patients on hemodialysis for more than 30 years (" $30+$ " group) and for comparison, 13 patients on hemodialysis for 20-30 years ("20-30" group) at Sangenjaya Hospital were enrolled in this study. The frequencies of operations for conditions related to hemodialysis-related amyloidosis were examined. Kaplan-Meier's analysis was used to estimate the history of operation and the log-rank test was used to compare the history of operation between the two groups. Results: The mean age at the start of hemodialysis was younger in the " $30+$ " group $(29.1 \pm 7.3$ years $)$ than in the " $20-30$ " group $(40.5 \pm 8.2$ years, $\mathrm{p}=0.0003)$. Eighteen $(85.7 \%)$ patients had undergone operation for CTS, 6 (28.6\%) had undergone surgery for trigger finger, and $6(28.6 \%)$ had undergone surgery for cervical destructive spondyloarthropathy (DSA) at 30 years after the start of hemodialysis therapy. Patients who were over the age of 30 years at the start of dialysis therapy more frequently underwent CTS and cervical DSA operations $(100 \%, 62.5 \%$, respectively) than those who were under 30 years of age at the start of dialysis $(76.9 \%$; $p=0.025$, $7.7 \% ; p=0.003$, respectively) in the " $30+$ " group at 30 years after the start of hemodialysis. The frequencies of operations for CTS did not differ significantly between the "20-30" group (23.1\%) and the " $30+$ " group $(23.8 \%)$ at 20 years after the start of hemodialysis. Conclusion: Hemodialysis-associated amyloidosis was common in extremely long-term survivors. Even though the mean age at the start of hemodialysis was younger in the " $30+$ " group than in the "20-30" group, the frequency of operations for CTS did not differ. This may be attributable to the recent advances in hemodialysis technologies.

\section{5 \\ Muscle Atrophy, Inflammation and Clinical Outcome in Incident and Prevalent Dialysis Patients}

\author{
J.J. Carrero, J. Axelsson, O. Heimbürger, P. Bárány, \\ B. Lindholm, P. Stenvinkel, A.R. Qureshi (presenting) \\ Divisions of Renal Medicine and Baxter Novum, \\ Karolinska Institutet, Stockholm, Sweden
}

Background and aims: Muscle wasting is a marker of proteinenergy wasting in end-stage renal disease (ESRD). We tested the 
association between a simple muscle atrophy (MA) grading system with morbidity and mortality in ESRD patients. Patients and Methods: In two different ESRD cohorts (265 incident patients starting dialysis and 221 prevalent hemodialysis patients), each patient's degree of MA was visually graded by a trained nurse on a scale from 1 to 4 . We next compared inflammatory and nutritional indexes between MA grades as well as survival in each group during a follow-up of 4 and 6 years, respectively. Results: $30 \%$ of the incident and $39 \%$ of the prevalent patients were defined as having MA. With increasing MA score, nutritional and anthropometric markers of muscle mass were incrementally poorer while inflammation increased. Female sex, presence of cardiovascular disease, inflammation and low insulin-like growth factor-1 levels were associated with higher significant odd ratios of MA in each cohort. After adjustment for age, sex, inflammation, diabetes, cardiovascular disease, glomerular filtration rate and time on hemodialysis, the hazard ratio of death for moderate/severe MA was 2.62 (95\% CI: 1.34, 5.13; p = 0.001) and 3.04 (95\% CI: $1.61,5.71 ; \mathrm{p}=0.0001)$ in the incident and prevalent cohorts respectively. Conclusion: A simple MA score was able to identify patients with signs of inflammation, poor nutritional and anthropometric status, as well as a higher mortality in two separate cohorts of incident and prevalent patients.

06

\section{Replacement of Renal Function with Haemodialysis in Very Old Patients}

\section{P. Kes (presenting), N. Bašic'-Jukic', I. Jurić \\ Department of Dialysis, University Hospital Centre \\ Zagreb, Zagreb, Croatia}

Background: Octogenarian patients have, until recently, been treated with conservative measures while they were believed to have too poor prognosis on renal replacement therapy (RRT). We prospectively investigated clinical characteristics and outcome of octogenarian patients treated with haemodialysis (HD) for at least 2 years. Methods: Twelve patients who were older than 80 years at the start of HD were included in investigation. Their clinical characteristics, etiology of renal disease, nutritional status, complications, comorbidities, vascular access, hospitalizations, compliance and outcome were recorded. Results: Dialysis was initiated in an emergency situation in $64.3 \%$. Vascular access was long-term HD catheter in $71.4 \%$ of octogenarians. Primary renal disease was unknown in $42.8 \%$ of patients. Comorbid conditions were present in all patients. Erythropoietin was prescribed in $14.2 \%$. There were no major bleeds with reduced doses of heparin. The most common complications were catheter-related (infections, ruptures). All patients together required 7 hospitalizations per year (0.58 per patient). One year survival was $71.4 \%$, and two-year survival was $50 \%$. Conclusion: Most of octogenarian patients died from causes that were not related to the endstage renal disease. Survival rate was satisfactory and justify treatment of this age group. However, their treatment requires a careful planning of renal service expansion while more octogenarians who need renal replacement treatment may be expected. Numerous ethical dilemmas further complicates treatment of octogenarian patients with HD.

26th Annual Meeting of the International

Society of Blood Purification (ISBP)
07

\section{Various Patterns of Hepatitis C Virus Viremia in Hemodialysis Patients}

A. Sikole (presenting), P. Dzekova, A. Asani, G. Selim, S. Pavleska, L. Stamatov, N. Stojcev, S. Gelev, V. Amitov

University Clinic of Nephrology, Skopje, R. Macedonia

Objectives: A striking feature of hepatitis $\mathrm{C}$ virus infection (HCV) infection is a very high rate of chronicity, with $80-90 \%$ patients developing chronic infection with persistent viremia and detectable HCV RNA. Serial examinations of the HCV viral load showed the presence of a fluctuating course of viremia over time in HCV infected patients on maintenance hemodialysis. The study was designed to evaluate the presence of HCV RNA in HCV antibody positive hemodialysis patients. Methods: Our study was made on $65 \mathrm{HCV}$ antibody positive patients ( 38 men and 27 women, mean age 54.1 years (range: 27-82), and mean time on dialysis 148 months). Duration of HCV infection was estimated from the time of first detection of HCV antibodies. The presence of HCV antibodies was determined by ELISAthird generation assay. The presence of the HCV RNA in serum in $\mathrm{HCV}$ antibody positive patients was assessed by reverse-transcriptase PCR (RT/PCR), three times over a period of 12 months. One way ANOVA was used for group mean comparison between the three different groups of patients according to HCV RNA status. Results: From $66 \mathrm{HCV}$ antibody positive patients, $30(46.2 \%)$ were HCV RNA persistently positive, $10(15.4 \%)$ were HCV RNA persistently negative, and $25(38.5 \%)$ had intermittent viremia, after assessment of viral status three times over a period of 12 months. HCV RNA persistently positive patients had significantly higher levels of ALT (50.07 \pm 30.0 vs. $28.5 \pm 10.0 \mathrm{U} / \mathrm{L}, \mathrm{p}<0.027)$ compared to HCV RNA persistently negative patients. There was no significant difference in serum level of ALT between HCV RNA persistently positive and HCV RNA persistently negative patients compared to patients with intermittent viremia. Also there was no significant difference between the three groups according to the age, dialysis duration, duration of HCV infection, serum levels of AST and bilirubin, and the number of transfusions. Conclusion: Various patterns of HCV viraemia had been observed in our study: persistently and intermittently HCV RNA positive patients, and persistently HCV RNA negative patients. Intermittent viremia could be caused by the adsorption of HCV RNA onto inner surface of dialyzers and destruction of viral particles by the hydraulic pressure exerted by the blood for dialysis. In fact, hemodialysis procedure lowers the viral load in serum below the detection limit of PCR.

08 ISBP Trustees Best Abstract Award

Estimation of Hydratation Status in Patients on Hemodiafiltration (HDF) - Comparison of Different Methods (BCM, US-VCI, BVM)

\author{
K. Nehézová, O. Remeš, J. Verešová, M. Portová, I. Rychlík \\ (presenting) \\ Dialysis Unit, FMC, Prague - Vinohrady, Czech Republic
}

Objectives: Overhydratation is a common problem on maintenance dialysis treatment and thus the estimation of "dry weight" could 
be rather difficult challenge. BCM (Body Composition Monitor) represents a new instrumental method to assess the "normohydratation" status. Aim: To assess the hydratation status using BCM and to compare it with US-VCI method (ultrasound measurement of vena cava inferior collapsible index after HDF), BVM (Body Volume Monitor) and the clinical status. Methods: during one single HDF treatment we performed measurements using BCM (multifrequency bioimpedance spectroscopy), US-VCI and BVM (ultrasound on line hematocrit measurement and evaluation of RBV/relative blood volume/ curve during HDF). The results were compared and correlated with objective clinical status. All pts were on maintenance ( $>90$ days) on-line post-dilution HDF using F5008 monitor. Results: 38 pts, M/F ratio $71 / 29 \%$, mean age 70.8 yrs $( \pm 15)$, mean treatment time 29 months (4-114 months), 35\% were diabetics. Average intradialytic weight gain was $2.15 \mathrm{~kg}$ and hypertension had $32 \%$ pts $(\mathrm{BP}>140 / 90 \mathrm{mmHg}$ before HDF). The percentage of hyper/normo/hypohydratation pts was $24 / 55 / 21 \%$ according to BCM and $11 / 78 / 11 \%$ according to USVCI, respectively. Positive correlation between BCM and US-VCI results was found in $77 \%$. When light hyperhydratation was found by $\mathrm{BCM}$, the normo/hypohydratation according to US-VCI was found in $8 \%$ of pts. In BVM, the RBV curve corresponding with intravascular (IVC) hypovolemia was found in $13 \%$, but $80 \%$ out of these pts were assessed as normo/hyperhydratation by both BCM and US-VCI. When normohydratation was found by both BCM and US-VCI, the mean value of RBV was $87.5 \%$. Conclusions: $1 / \mathrm{BCM}$ seems to be a method with good correlation to clinical hydratation status; 2/ discrepancy between the RBV hypovolemia curve vs. BCM/US-VCI normo/hypervoleamia is probably due to poor or prolonged refill of IVC during or after HDF treatment, despite of relative interstitial hyperhydratation.

\section{9}

\section{Assessment of Fluid Status in Dialysis Patients by Means of Terahertz Spectroscopy}

\section{F. Lopot ${ }^{1}$ (presenting), V. Polakovič , F. Kadlec ${ }^{2}$, M. Berta ${ }^{2}$, P. Kužel ${ }^{2}$}

${ }^{1}$ General University Hospital, ${ }^{2}$ Institute of Physics, Academy of Sciences, Prague, Czech Rep.

Objectives: Reliable assessment of fluid status in haemodialysis (HD) patients is a persisting problem. Recently, terahertz timedomain spectroscopy (TDTS) was used to identify cancerous tissue, based on its different water content and strong interaction of water molecules with $\mathrm{THz}$ radiation. This study tried for the first time to apply TDTS for assessment of fluid status in HD patients. Method: TDTS $\left(80 \mathrm{MHz}\right.$ pulses in frequency region of $\left.0,2-1,5^{*} 10^{12} \mathrm{~Hz}\right)$ measurements were performed in 10 stable HD patients prior to and after 2 HD sessions, one after 3 days and one after 2 days interval. From the reflected THz pulse, the phase shift $\varphi$ and amplitude rescaling factor $\boldsymbol{r}$ were evaluated at 2 sites on volar forearm and tip of the ring-finger (non-access arm). Pre-HD vs. post-HD changes in $\varphi$ and $\boldsymbol{r}$ values were evaluated and compared with fluid volume (UF) removed during HD and changes in excess fluid evaluated by bioimpedance spectroscopy (BCM, Fresenius). Results: During most of the investigated HD sessions the amplitude factor $\boldsymbol{r}$ measured at the forearm increased (by 2 to $38 \%$ ), changes at the finger-tip were far less pronounced. Changes in $\varphi$ with UF were clearly visible in some patients, but negligible in others. Crosscorrelation in both $\boldsymbol{r}$ and $\varphi$ measured at different locations was quite good, the proportioning coefficient was however always far from 1.0, suggesting differing tissue properties in different measuring sites. The weakest statistically insignificant correlations were seen between the changes in $\varphi$ and $\boldsymbol{r}$ and conventional markers of fluid status changes (BCM-measured overhydration and UF), although there was a clear impact of small number of measurements (R-value doubled when data of two "outlier" patients were excluded). Conclusions: This very first small-scale study demonstrated measurable changes in TDTS parameters pre- vs. post-HD. Unsatisfactory correlations of those changes with changes in fluid status call for testing other skin measurement sites and/or modifying the skin conditions.

\section{0 \\ Value of Serum Biomarkers in the Assessment of Bone Turnover, Mineralization, and Volume in Hemodialysis Patients \\ G. Asci', F. Kircelli1 (presenting), E. Sevinc ${ }^{1}$, M. Yilmaz', S. Duman', M. Ozkahya', H. Toz', F.M.C. Monier², H.H. Malluche ${ }^{2}$, E. OK $\mathrm{K}^{1,3}$ \\ ${ }^{1}$ Ege University, ${ }^{2}$ Kentucky University, ${ }^{3}$ FMC Turkey, Turkey}

Objectives: We investigated value of serum bone markers for assessment of bone turnover $(\mathrm{T})$, mineralization $(\mathrm{M})$, and volume $(\mathrm{V})$ in hemodialysis (HD) patients. Methods: Bone biopsy (BB) was done after tetracycline double labeling in 218 prevalent HD patients. Mean age was $57 \pm 14$ year, HD duration $53 \pm 45$ months. T, M, and V were assessed by static and dynamic measurements at standardized sites in cancellous bone using the semi-automatic method (Osteoplan II). Intact PTH levels were measured by IRMA (Scantibodies); bone alkaline phosphatase (BAP), cross-linked N-telopeptide of type 1 collagen (NTx), tartrate-resistant acid phosphatase (TRAP), osteoprotegerin and RANKL levels were measured by ELISA in blood samples obtained at the time of BB. ANOVA and multivariate analysis were done. Results: Of all BB specimens (BBs), $58 \%$ of BBs labeled with tetracycline was diagnosed as low-T, 17\% as high-T. Frequency of the patients with normal/high-V was $56 \%$. Defective mineralization was found in only 5 patients; none of them had low T. In patents with high-T, mean PTH, ALP, NTx, BAP, and TRAP levels were significantly higher, OPG/RANKL ratio lower, compared to those with low-T. BAP, NTx, TRAP and ALP levels were significantly higher in patients with defective mineralization. Only NTx levels demonstrated a correlation with $\mathrm{V}$. In multivariate analysis adjusted for age, gender, presence of diabetes, HD duration, only age and serum NTx were significantly predictive for T [CI: $1.003(1.001-1.005), \mathrm{p}<0.01]$. None of the markers studied was predictive for $\mathrm{V}$ and $\mathrm{M}$. Conclusion: Bone turnover can be better predicted by BAP, NTx, and ALP than PTH. No marker was found for prediction of V. The low number of patients with defective $\mathrm{M}$ does not lend itself for analysis. 


\section{1}

On-Line Hemodiafiltration: TMP Ultracontrol vs. UF Control

\author{
M. Gonella1 (presenting), G. Calabrese', I. Quaglio', \\ C. Baldin', G. Vagelli', A. Mazzotta', S. Berutti', S. Rindi', \\ P. Deambrogio ${ }^{2}$ \\ ${ }^{1}$ Renal Unit and ${ }^{2}$ Laboratory of Clinical Pathology \\ Ospedale S. Spirito - ASL AL Casale Monferrato - Italy
}

Background: On-line HDF with high UF has been reported to be associated with a reduced mortality risk as compared to HD, because of the improved small and large molecules removal, of the better vascular stability and the higher biocompatibility. High UF postdilution is generally considered the best mode for HDF; however, the recommended $\mathrm{Hb}$ targets limit UF and efficiency because of hemoconcentration. Since in postdilutional HDF TMP Ultracontrol (TMP POST-HDF) enhances UF as compared to UF control (UF POSTHDF), its possible advantages were evaluated. Methods: After establishing the infusion volume and the heparin dose in order to avoid partial clotting of fiber fibers and not to exceed the recommended limits of hydraulic pressures, 46 stable patients with adequate blood flow ( $400 \mathrm{ml} / \mathrm{min}$ ) in HDF with UF control (26 in post, 20 in predilution), were transferred to TMP POST-HDF for six months. In TMP POSTHDF the maximum TMP is set automatically at the start of the session according to the operative conditions; thereafter TMP is controlled by the system at regular intervals, in order to obtain the optimal convection for each treatment. The same parameters were evaluated and compared during the last two months in UF HDF and in TMP POST-HDF. Results: During TMP POST-HDF: UF was higher than on UF POSTHDF ( $98 \pm 8$ vs. $73 \pm 7 \mathrm{ml} / \mathrm{min}$ ) and similar to UF PRE-HDF $(97 \pm 21)$; heparin dose was reduced; hemoglobin remained unchanged $(11.8 \pm 1.1$ and $12 \pm 1.1 \mathrm{~g} / \mathrm{dl})$ despite EPO reduction; $\mathrm{sCr}$ and $\mathrm{sB} 2 \mathrm{M}$ decreased significantly (from $8.9 \pm 2$ to $8.4 \pm 2 \mathrm{mg} / \mathrm{dl}$ and from $28 \pm 4$ to $26 \pm 4 \mathrm{mg} / \mathrm{l}$, respectively, $\mathrm{p}<0.01$ in both cases); sPi remained unchanged despite less chelating agents $(4.8 \pm 1.3$ and $4.6 \pm 1.1 \mathrm{mg} / \mathrm{dl})$; $\mathrm{sAlb}$ increased significantly (from $4.2 \pm 0.3$ to $4.4 \pm 0.3 \mathrm{~g} / \mathrm{dl}$ ). Conclusion: TMP Ultracontrol increased UF in POST-HDF in patients with the recommended $\mathrm{Hb}$ targets, guaranteeing good rheological conditions and improving biochemical parameters as compared to other efficient HDF modalities. Therefore, postdilution with TMP Ultracontrol seems to be the optimal strategy for HDF.

\section{2 \\ Thrombogenicity of Three Different Anticoagulation Methods without Systemic Effect \\ P. Richtrova (presenting), K. Rulcova, T. Reischig \\ Department of Internal Medicine I, Charles University, Medical School and Teaching Hospital Plzen, Czech Republic}

Objectives: Contact between blood and artificial material of extracorporeal circuit (ECC) during hemodialysis (HD) induces activation of coagulation. Anticoagulants infused during $\mathrm{HD}$ reduce this activation. Sometimes it is not possible to use systemic anticoagulation, for example in patients with bleeding complications. In our study we compared parameters of thrombogenicity during HD with three different anticoagulation methods without systemic anticoagulation effect. Methods: In $10 \mathrm{HD}$ patients we compared in a prospective, crossover and randomized study plasma concentrations of thrombin-antithrombin complexes (TAT) and platelet factor 4 (PF 4) during procedure with 1. regional citrate anticoagulation (RCA), 2. regular saline flushes of ECC and 3. AN69 ST membrane after priming according to manufacturer recommendation. Results: All 10 HD with RCA was finished after $240 \mathrm{~min}$ as scheduled. Because of ECC clotting, 6/10 procedures with saline flushes and 5/10 with AN69 ST were finished prematurely $(\mathrm{p}=0.011$ and $\mathrm{p}=0.033$, resp., Fisher exact test). Compared to preHD values, there was a significant increase in TAT during HD (minute 60, 120 and 240) with RCA $(0.55$ $\mu \mathrm{g} / \mathrm{L}$ vs. 14.6 vs. 10.6 vs. 8.4, p $<0.001$, medians, Friedman Repeated Measures Analysis of Variance of Ranks), with saline flushes $(0.2 \mu \mathrm{g} / \mathrm{L}$ vs. 118.7 vs. 157.3 vs $242.9, \mathrm{p}<0.001)$ and with AN69 ST membrane $(0.6 \mu \mathrm{g} / \mathrm{L}$ vs. 92.0 vs. 134.7 vs. $124.0, \mathrm{p}=$ $0.001)$. The increase was significantly higher during HD with saline flushes and AN69 ST compared to RCA ( $<<0.05)$. Plasma concentrations of PF4 increase along HD but there was not significant difference between the anticoagulation methods. Conclusion: Based on TAT levels, there is evident coagulation activity during HD with RCA. However, the activation is significantly lower compared to HD with saline flushes and AN69 ST membrane. RCA seems to be the most convenient method. AN69 ST membrane is comparable to HD with saline flushes with no additional benefit for thrombogenicity.

\section{3 \\ Lock Spillage from Catheters with and without Side Holes}

\section{H.D. Polaschegg (presenting) \\ Medical Devices Consultant, Koestenberg, Austria}

Objectives: Between treatments catheters are filled with locking solution, usually heparin. Approximately $25 \%$ of the solution is spilled immediately if the filling volume of the catheter lumen is injected into straight cylindrical tubing. In this work locking solution spillage with catheters of the same type but with and without side holes was measured and normalized with the filling volume. Methods: 1 . A red dye solution was injected into the catheter with the tip placed in a beaker containing $0.9 \% \mathrm{NaCl}$ solution. 2 . The catheter was filled with red dye solution and slowly lowered into the beaker containing a more dense $1.8 \% \mathrm{NaCl}$ solution. In both cases the fluid in the beaker was stirred and the spilled volume was measured on-line with a fiberoptic photospectrometer with dip-probe. Results: 1 . Spillage for the Medcomp SplitCathIII was $>20 \%$ of the measured filling volume. There was no difference between catheters with and without side holes. 2. The dip experiment revealed that the tip of the catheter without side holes is immediately washed out. The complete region of the catheter between tip and the most distal side hole is washed out in catheters with side holes. Visually it can be observed that the locking solution streams upward through the most distal side hole if the locking solution density is lower than the density of the fluid in the beaker. Conclusion: Lock spillage from the SplitCathIII deviates little from theory for 
cylindrical tubing which allows the conclusion that locking solution concentration close to the tip is only $50 \%$ in the catheter without side holes and zero in the side hole region.

\section{4}

Convective Forces Across the Membrane with Opposite Phase Double Pulsation Flow in the Wearable Artificial Kidney (WAK)

\author{
V. Gura (presenting), M. Beizai, C. Ezon
}

Sinai Medical Center. UCLA. The David Geffen School of Medicine, Beverly Hills, CA USA

Mounting evidence indicates that unacceptably high morbidity and mortality in ESRD may be improved with more hours and more frequent dialysis. The WAK may be the most practical and cost effective way of achieving this goal by delivering ambulatory continuous push pull internal filtration. We analyzed flow and pressures patterns and convective characteristics of the opposite phase double pulsating mechanism of the WAK at blood and dialysate entry and exit ports of the dialyzer. Flow patterns of blood and dialysate in a single hollow fiber were visualized using a Vevo 770 High resolution ultrasound. Pressure analysis during the pulsation cycle indicated a TMP of $+150 \mathrm{mmHg}$ between blood and dialysate compartment changing to $-10 \mathrm{mmHg}$ in the opposite direction and intermittently repeating these direction changes 120 times per minute. The Doppler ultrasound images in single fiber confirm the pressure and flow data. Intermittent inversion of transmembrane pressure gradients with pulsatile flow in opposite phase of both blood and dialysate result in direct convective filtration drag from the lumen into the dialysate compartment mostly in the proximal aspect of the fiber. Back filtration of fresh dialysate into the lumen is created in the distal part of the fiber creating a "post dilution" effect along the hollow fiber. "Push-pull" flux due to back and forth inversions of TMP gradients direction may preserve the patency of the membrane pores. WAK performance meets or exceeds conventional and even quotidian dialysis results. Significant convection may improve mass transfer and explain these effects.

\section{ISBP Trustees Best Abstract Award Osteoprotegerin and Matrix-Gla Protein: Independent Predictors of Mortality in Hemodialyis Patients}

\author{
E. Sevinc ${ }^{1}$ (presenting), F. Kircelli', G. Asci ${ }^{1}$, M. Yilmaz', \\ D. Bozkurt ${ }^{1}$, M. Ozkahya ${ }^{1}$, A. Basci ${ }^{1}$, E. Ok ${ }^{1,2}$ \\ Division of Nephorlogy, School of Medicine, ${ }^{1}$ Ege \\ University and ${ }^{2}$ FMC Turkey, Bornova, Izmir, Turkey
}

Objectives: In this prospective clinical study, we investigated the associations of serum fetuin A, osteoprotegerin (OPG), and matrix-gla protein (MGP) levels with mortality in hemodialysis (HD) patients. Methods: 545 maintenance HD patients were prospectively followed-up for 18 months (Mean age $58 \pm 13$ years, $46 \%$ female). Fetuin
A (Biovendor), OPG and MGP (Biomedica) were measured by ELISA. Demographical, clinical and laboratory data were recorded. Cox regression was used to analyze overall mortality and Kaplan-Meier for cumulative survival. Results: Mean fetuin A level was $0.24 \pm 0.06 \mathrm{~g} / \mathrm{l}$ (0.08-0.52), OPG 10.6 $\pm 5.9 \mathrm{pmol} / \mathrm{L}(1.8-41) \mathrm{MGP} 9.8 \pm 3.2 \mathrm{nmol} / \mathrm{L}$ (1.3-25.6). Overall mortality was $10.3 \%$ (n: 56). Patients who died were older $(65 \pm 10$ vs $57 \pm 14$ yrs, $\mathrm{p}<0.001)$, more diabetic (38 vs $22 \%, \mathrm{p}<0.01)$, had higher serum OPG levels $(13.8 \pm 7.5$ vs $10.2 \pm 5.4 \mathrm{pmol} / \mathrm{L}, \mathrm{p}<0.001)$, lower serum albumin $(3.7 \pm 0.3$ vs $3.9 \pm 0.3 \mathrm{~g} / \mathrm{dl}, \mathrm{p}<0.01)$ and MGP levels $(8.5 \pm 3.1 \mathrm{vs} 9.9 \pm 3.2 \mathrm{nmol} / \mathrm{L}$, $\mathrm{p}<0.01)$ compared to those alive. Fetuin A levels were not different in patients who died or alive. Multivariate analysis revealed that age, diabetes and CRP levels were predictors of mortality. Then fetuin A, OPG, and MGP was added in the model separately; OPG (with age) and MGP (with CRP and age) were predictive for mortality, whereas fetuin A was not. When fetuin A, OPG and MGP were added together to the model, only age (RR: $1.04, \mathrm{p}<0.01$ ), serum OPG (RR: $1.06, \mathrm{p}<0.01$ ) and MGP (RR: $0.88, \mathrm{p}<0.01)$ were found as independent mortality predictors. In medium- and high-OPG tertiles $(>12.1 \mathrm{pmol} / \mathrm{L}), \mathrm{RR}$ for mortality was 1.7 and 2.5 compared to low-OPG group $(<7.1 \mathrm{pmol} / \mathrm{L})$ $(\mathrm{p}<0.05)$. Compared to low-MGP group $(<8.5 \mathrm{nmol} / \mathrm{L})$, RR for mortality was 0.32 in high-MGP group $(>10.9 \mathrm{nmol} / \mathrm{L})(\mathrm{p}<0.01)$. Conclusion: Higher OPG and lower MGP levels are independent predictors of mortality in hemodialysis patients.

\section{6 \\ The Long Forgotten Salt Factor}

Stanley Shaldon (presenting)

Monaco

The lack of evidence based medicine proof and dietary compliance in ESRD patients have resulted in the abandonment of salt restriction in ESRD patients. However, occasionally, new ideas resuscitate these forgotten paradigms. The reason for this may be traced to an empirical observation of a delayed improvement in blood pressure control of patients on salt restriction, namely "the lag phenomenon" This phenomenon results from a reduction in peripheral resistance. The explanation may be linked to the reduction of non-osmotically active sodium which is bound to the interstitial matrix lining the intimal surface of blood vessels containing proteoglycans and glycosaminoglycans. This sodium store takes months to normalize on a $5 \mathrm{~g}$ salt intake. The concept depends upon observations in vitro that the gene responsible for inducing the inflammatory cytokine cycle, MAPK38 (Mitogen activated protein kinase) is stimulated by a local high sodium concentration; and results in an ADMA (asymmetric dimethyl arginine) induced increase in peripheral resistance by reduction in nitric oxide synthesis which will be reversed by a low salt dietary intake, as will the production of inflammatory cytokines and consequent endothelial damage. Thus, the lesson to be learned from the almost unique experiences of Tassin and Izmir is that the most important determinant of improved survival in ESRD patients on haemodialysis is less related to the technical aspects of therapy, than to the insistence of a $5 \mathrm{~g}$ daily salt intake. The tragedy of this conclusion is that the tendency to increase the salt intake of the world's population by the spread of processed food and instant cooking make the problem of adherence to such a diet more difficult to achieve. 


\section{7}

\section{Plasma Exchange in Elderly Population}

\author{
P. Kes, B. Brunetta-Gavranic', N. Bašic'-Jukic', \\ Lj. Bubic'-Filipi, Z. Puretic', S. Glavaš-Boras
}

Department of Dialysis, University Hospital Centre Zagreb, Zagreb, Croatia

Objectives: Indications for use of plasma exchange (PE) are limited on several diseases occurring mostly at younger age. In the present study we investigated indications for PE in elderly patients. Methods: We analyzed retrospectively Department of Dialysis, Zagreb University Hospital Center's database for indications, complications and epidemiology of patient aged 65 and older submitted to PE. Database includes data on 634 patients, or 6237 PE treatments, gathered in period from 1982-2007. Results: A total of 50 patients aged 65 and older ( $7.9 \%$ of all patients) were submitted to PE during that period. Median age was 69 years, with oldest patient being 83 years old. This population was submitted to $323 \mathrm{PE}$ (5.2\% of all PE). Mostly used replacement fluid was 5\% albumin solution ( $94.0 \%$ ), and blood accesses were usually peripheral veins (72.0\%). Majority of indications $(76.0 \%)$ were in field of neurology (myasthenia gravis, and Guillain-Barré syndrome), which were more common than in entire population of database $(56.2 \%)$. Second most common indications were hematological (hyperviscosity syndrome, and thrombotic thrombocytopenic purpura due to malignancy; $18.0 \%$ vs. $9.5 \%$ ), followed by intoxications and rapidly progressive glomerulonephrits. Complications occurred during 37 procedures (11.5\%), more often than in the database population $(7.4 \%)$. The most common complications were clotting $(3.7 \%)$, blood access difficulties (1.5\%), mild to moderate allergic reactions (1.5\%) and precordial oppressions $(0.6 \%)$. The incidence of severe, potentially life-threatening adverse reactions was $0.3 \%$. The prophylactic use of calcium and potassium was responsible for a low incidence of electrolyte disturbances. There was no lethal outcome associated with PE. Conclusion: PE is procedure rarely used in elderly population, but when carried out by experienced staff, it can be used in all indications with only few more side effects, and with good results.

\section{8 \\ Development of Extracorporeal Blood Purification Methods: MARS: An Important Goal in the Treatment of the Liver Failure}

\section{R. Marangoni (presenting) \\ Liver Unit, S.Giuseppe Hospital, Milan, Italy}

Objectives: To evaluate the efficacy of MARS (Molecular Adsorbent Recirculating System) in the treatment of the liver failure. Method: MARS treatment have been applied to 81 patients, 6 with acute liver failure (group A) and 75 with acute-on-chronic liver failure (8 complicated by renal failure - hepatorenal syndrome) (group B). 31 of patients from group B lamented severe pruritus refractory to pharmacological therapy and showed scratching skin lesions. The treatments have been performed according to the following modalities: 2-7 daily sessions according to the patient needs; session time:
5 hours; blood flow $220 \pm 20 \mathrm{ml} / \mathrm{min}$; albumin flow $150 \mathrm{ml} / \mathrm{min}$; dialysate (in the albumin dialyzer) $500 \mathrm{ml} / \mathrm{min}$; heparin $750 \mathrm{U} /$ hour (on the average). Bilirubin, bile acids, ammonia, urea, creatinine, plasma electrolytes, acid-base balance were determined at the beginning and at the end of each session, and cholinesterase, prothrombin activity, AST, ALT, GGTP were assessed before and after the MARS cycle. Results: At the end of each treatment bilirubin, bile acids, and ammonia fell of $27-54 \%$ of $27 \pm 7 \%, 40 \pm 5 \%$ and $54 \pm 14 \%$ respectively. After the MARS cycle bilirubin, bile acids, ammonia, alkaline phosphatase significantly decreased $(p<0.001)$, while cholinesterase and prothrombin activity significantly increased $(\mathrm{p}<0.002)$. AST, ALT and GGTP did not change in group B, while the same parameters decreased in patients affected by acute liver failure, who were on the way of recovery after MARS cycle. In group B, 61 patients showed an evident improvement of clinical conditions and liver function. 5 of the 8 patients with hepatorenal syndrome, reached a complete recovery of the renal failure, at the same time of an improvement of liver failure. Severe pruritus disappeared in all cases after the second or the third MARS treatment. Conclusion: These results confirm that MARS treatment can significantly improve the prognosis of the liver failure.

\section{9}

\section{Extracorporeal Liver Support Therapy as a Bridge to Liver Transplantation}

\author{
K. Mihovilovic', I. Kovačevic'-Vojtušek, S. Gracin, T. Filipec \\ Kanižaj, S. Naumovski Mihalić, M. Knotek (presenting) \\ Renal Replacement Therapy Section, Renal Division, \\ Department of Medicine, Clinical Hospital Merkur, Zagreb, \\ Croatia
}

Introduction: Fractionated plasma separation and adsorption with hemodialysis (Prometheus) is a novel method of extracorporeal replacement therapy used in liver failure. It allows for simultaneous removal of albumin-bound and water-soluble substances from plasma. Method was developed in 1999, and it has been used in Merkur hospital since 2007. It has been used as a bridge to liver transplantation or to the spontaneous recovery of liver function in case of acute or acuteon-chronic liver failure. Aim of this investigation was to assess efficacy of Prometheus in liver transplant candidates presenting with acute, acute-on-chronic, or with severe deterioration of chronic liver failure. Methods: We analyzed data on Prometheus use in patients hospitalized in Merkur hospital, who were candidates for liver transplant. Indication for liver support therapy was chronic or acute liver failure with encephalopathy $\geq 2$ grade. Each treatment was performed for $6 \mathrm{hrs}$, and was repeated every $2^{\text {nd }}$ day until transplantation, recovery of liver function or death of patient occurred. Regional citrate anticoagulation was used. For assessment of the efficacy we measured total bilirubin, creatinin, urea and ammonia before and after each treatment. For safety analysis data on arterial blood pressure, venous blood $\mathrm{pH}$ and base deficit, as well as INR before and after each treatment were recorded. Results: 9 patients were included who satisfied above criteria $(6 \mathrm{~m}$. and $3 \mathrm{f}$.). Age median was 42 y. (16-52 y.). Total number of procedures was 22 (average 2.4/patient). Mean bilirubin reduction during the procedure was $29.12 \pm 3.4 \%$, ammonia reduction was $23.27 \%$, and for urea it was $56.68 \pm 4.00 \%$. Concentrations of total 
bilirubin and urea were significantly lower after the Prometheus treatment as compared to values before treatment $(p<0.01)$. Serum albumin, INR, $\mathrm{pH}$, base deficit and mean arterial pressure did not change significantly with the Prometheus treatment. In patients who were subject to more than one procedure, a dynamics of biochemical parameters was determined. Thus, there was a continuing reduction in serum concentration of total bilirubin $(\mathrm{p}<0.05)$, creatinin $(\mathrm{p}<0.05)$ and $\mathrm{pH}$ $(\mathrm{p}<0.001)$. Finally, patient survival to transplantation or liver function recovery was $66.7 \%(6 / 9)$. Conclusion: Liver support therapy by fractionated plasma separation and adsorption with hemodialysis is useful in bridging the period to liver transplantation, or recovery of liver function.

\section{0}

\section{Influence of the Local Inflammation of the Peritoneal Membrane on the Residual Renal Function in Patients Treated with Peritoneal Dialysis}

I. Jeličic' (presenting), D. Ljutic', G. Pehar, T. Filipovic', M. Šain, D. Boric' Śkaro, V. Wilhelm, V. Kovačic', J. Radic'

Department of Nephrology and Dialysis, Internal Clinic, Clinical Hospital Split, Split, Croatia

Objectives: We conducted this study to investigate the connection between local inflammation of peritoneal membrane, monitoring a level of effluent interleukin-6 (IL-6), and the residual renal function, and peritoneal solute transport rate (PSTR) in patients treated with continuous ambulatory peritoneal dialysis (CAPD). Methods: Twenty patients on treatment with CAPD of the Department of nephrology and dialysis Clinical Hospital Split participated in crosssectional study. IL-6 and soluble interleukin-6 receptor (sIL-6R) were measured in plasma and in overnight effluent. Peritoneal equilibrium test was performed using 3,86\% glucose dialysate solution, and PSTR of small solutes was evaluated using dialysate-to-plasma ratio $(\mathrm{D} / \mathrm{P})$ of creatinine after 4-hour dwell. Results: Mean concentration of the effluent IL-6 was 7,87 $\pm 2,62 \mathrm{pg} / \mathrm{ml}$, effluent sIL-6R 299,1土 $114,9 \mathrm{pg} / \mathrm{ml}$, serum IL-6 $1,29 \pm 0,78 \mathrm{pg} / \mathrm{ml}$ and serum sIL-6R $13227,5 \pm 4852,4 \mathrm{pg} / \mathrm{ml}$. There was not significant correlation between effluent IL- 6 and residual renal function (RRF) ( $r=-0,288$, $\mathrm{p}=0,218)$, but there was significant negative correlation between effluent IL-6 and diuresis $(r=-0,533, p=0,015)$. There was significant correlation between $\mathrm{D} / \mathrm{P}$ creatinine after 4 hours and effluent IL-6 ( $\mathrm{r}=0,483, \mathrm{p}=0,031)$, between months performed on the CAPD and effluent IL-6 ( $\mathrm{r}=0,577, \mathrm{p}=0,008)$, and serum IL-6 $(\mathrm{r}=0,528, \mathrm{p}=0,017)$. Effluent IL-6 also correlated with serum IL-6 $(r=0,608, p=0,004)$, systolic blood pressure $(r=-0,557$, $\mathrm{p}=0,011)$, and LDL $(\mathrm{r}=-0,5, \mathrm{p}=0,029)$. Effluent sIL-6R correlated with patients age $(\mathrm{r}=0,488, \mathrm{p}=0,029)$, hemoglobin $(\mathrm{r}=-0,592, \mathrm{p}=0,006)$ and weakly dose of erythropoietin $(\mathrm{r}=-0,651, \mathrm{p}=0,002)$. There wasn't statistically significant correlation, but tendency of significances, between the $\mathrm{D} / \mathrm{P}$ creatinine and the RRF ( $\mathrm{r}=-0,399, \mathrm{p}=0,081)$ and the diuresis $(\mathrm{r}=-0,406$, $p=0,076)$. Conclusion: Results this study demonstrated that local inflammation of peritoneal membrane is significantly related with duration of CAPD treatment, with decreased diuresis, and with increased transport through the peritoneal membrane.

\section{1 \\ Removal of C Reactive Protein (CRP) from Blood of Patients with Acute Myocard Infarct (AMI)

\author{
A. Sheriff, B. Vogt, M. Möckel, R. Schindler, R. Kunze \\ (presenting) \\ Department of Nephrology and Intensive Care, Campus \\ Virchow, Charité, Berlin-Wedding, Germany
}

CRP is well known as an acute phase protein and marker for infection or trau-ma as in AMI. A decade ago, it was suggested that increases in its blood con-centration is a prognostic marker for the risk of cardiac events. Meanwhile, the suspicion grew that CRP is not only an indicator but a suspect in AMI. Pepys et al. demonstrated recently that CRP is in fact a culprit for the increase of the area of infarction. It can be assumed for a notable part of the affected patients that immunological processes enhance the destruction of involved heart areas via CRP-complement pathway. CRP binds to lysophosphatidyl-choline which is accessible in the membrane of necrotic and late apoptotic cells. Although this function is vitally important for the efficient clearance of materials from destroy-ed cells, an extended tissue destruction caused by high and especially long lasting levels of CRP is contra productive, prolongates the healing process and should therefore be corrected. Our therapeutic approach is to lower the concentration of CRP in blood of patients with AMI, after the infarct by selective apheresis. This may counteract the autocrine upregulation of CRP in concert with proinflammatory cytokines such as Interleukin $1 B$ and 6 . The elimination of CRP from blood will be per-formed by an adsorbing system which was designed for that purpose. To confirm our hypothesis about the pathological relevance of high levels of CRP in AMI first the device will be approved in animal experiments (pig, AMI model). Later on, clinical studies with AMI patients will be performed to reduce the area of infarction as well as the probability of a recurrent AMI. Data about the safety and performance of the CRP adsorbing system will be presented. 


\section{Poster Presentations}

P22

\section{A High Sensitive Urea Monitor for Hemodialysis}

\author{
M. Ozaki, T. Ishimaru, T. Okabayashi (presenting), \\ J. Hori, K. Hayashi, M. Nakagawa
}

Department of Disaster System, Faculty of Risk and Crisis Management, Chiba Institute of Science, Choshi, Chiba, Japan

Objectives: We propose a high sensitive and accurate monitor of urea in waste dialysate for the evaluation of hemodialysis efficiency. As it can measure the UN in waste dialysate at an interval of $3 \mathrm{~min}$, we can estimate the index of BUN of patients during hemodialysis therapy in situ. Method: The working mechanism of our urea monitor bases on chemiluminescence (CL) due to a chemical reaction between urea and sodium hypobromite ions. The monitor consists of a syringe ( $1 \mathrm{ml}$ in volume) to mix a sample solution of waste dialysate and sodium hypobromite solution, an electric slider to move a plunger of the syringe, and a photomultiplier to measure the CL-intensity. $0.16 \mathrm{ml}$ of waste dialysate was injected into the syringe, followed by an injection of sodium hypobromite solution of $1.14 \mathrm{ml}$. As the sodium hypobromite solution was flowed into the syringe through a narrow nozzle, turbulence occurred, and these two kinds of solutions were mixed quickly, and reproducible CL $(3.4 \%$ of relative standard deviation) was observed for repeated measurements of this procedure. Results: Just after these two kinds of solutions were mixed within the syringe of the urea monitor, CL was emitted, and a peak of the CL-intensity was observed after $1 \mathrm{~s}$. Good reproducibility of the CL was obtained under a condition of $40 \mathrm{~mm} / \mathrm{s}$ of plungerspeed and $0.16 \mathrm{ml}$ of sampling volume of waste dialysate and $1.14 \mathrm{ml}$ of sodium hypobromite solution. The reproducibility of the urea monitor was $3.4 \%$ of relative standard deviation. The CL-intensity was proportional to the concentration of UN ranging from 1 to $40 \mathrm{mg} / \mathrm{dl}$. The monitor could measure the UNs in waste dialysate at an interval of 3 min during the hemodialysis therapy of $4 \mathrm{~h}$ in a clinical application. The value of the UN measured by our urea monitor agreed very closely with that obtained by the conventional enzyme-method. Conclusion: Our urea monitor can measure the UN in waste dialysate in parallel with hemodialysis therapy at an interval of 3 min. This technology will contribute to estimate the index of BUN indirectly.
P23

\section{The Effect of On-Line HDF Using Acetate Free Fluid on Nutritional Status of Patients Underwent Maintenance Dialysis Therapy}

T. Tomo (presenting), M. Matsuyama, K. Matsuyama, T. Iwashita, K. Yufu, J. Kadota

Second Department of Internal Medicine, Faculty of Medicine, Oita Univeristy, Yufu, Japan

Objective: We investigated the effect of on-line HDF using acetate free fluid on nutritional status underwent maintenance dialysis therapy. Methods: A total of 24 maintenance hemodialysis patients were registered in this cross over study (mean age 58.2 \pm 14.5 y.o, mean dialysis duration $10 \pm 8$ yrs. M:F $=13: 11$ CGN21, DM2, PCK 1,NS 1). Firstly, 24 patients were treated with acetate included fluid for 3 months (Acetate-group), then the patients were treated with acetate free fluid for 3 months (Non acetate group). Laboratory data (CRP, leptin, NPY) in the serum or plasma and nutritional related data (PCR, Cr-index) were collected at 3 months after starting this study and thereafter 3 months. The filters (material or surface area) the conditions of HDF (pre dilution HDF modality, volume of replacement fluid, dialysis time, QB, QD, dry weight) and the drugs administrated were not changed during 6 months ( 3 months and 3 months) in each patient. Paired student's t-tests and Mann-Whitney U-tests were used when applicable to investigate differences between the two groups. Results: Serum CRP levels were significantly decreased in non acetate group $(0.096 \mathrm{vs} 0.055 \mathrm{mg} / \mathrm{dl} \mathrm{p}<0.05)$ compared with those in acetate group. Plasma leptin levels were significantly decreased in non acetate group $(3.28$ vs $2.57 \mathrm{ng} / \mathrm{ml} \mathrm{p}<0.05)$ compared with those in acetate group. Plasma NPY levels were significantly increased in non acetate group $(0.363$ vs $0.408 \mathrm{ng} / \mathrm{ml}$ $\mathrm{p}<0.05)$ compared with those in acetate group. Creatinine indexes were significantly increased in non acetate group (106.1 vs 110.8 $\mathrm{p}<0.05)$ compared with those in acetate group. Conclusion: From these results, the possibility that on-line HDF using acetate free fluid improved the nutritional status of patients underwent maintenance dialysis therapy is suggested.

\section{P24}

\section{Hemodialysis in Slovenia - Data from Slovenian RRT Registry 2006}

J. Buturovic' Ponikvar (presenting), for the Slovenian RRT Registry Group: T. Adamlje, D. Blanuša, Z.Ceglar, $S$. Cimerman-Steklasa, S. Černe, A. Cuufer, A. Drozg, R. Ekart, A. Guček, A. Kandus, S. Kapun, S. Kralj-Lopert, S. Kralj, M. Malovrh, M. Močivnik, G. Novljan, R. Ponikvar,

N. Rukavina, I. Rus, S. Saksida, B. Vujkovac

Department of Nephrology, University Medical Center Ljubljana, Slovenia

Objective: To present data on chronic hemodialysis (HD) treatment in Slovenia. Methods: Data from the Slovenian RRT Registry, on December 31, 2006, with emphasis on HD therapy, are presented. 
Response rate to individual patient questionnaires was $100 \%$. Results: The population of Slovenia is 2 million. There were 20 dialysis and 1 kidney transplant center. There were 1835 RRT patients (prevalence rate $913 \mathrm{pmp}$ ), incidence rate (day 1) $124 \mathrm{pmp} .69 .3 \%$ of RRT patients were treated by chronic HD $(\mathrm{n}=1271,55.2 \%$ men, median age 65 years, 17-93, 19.2\%-diabetic nephropathy, $24.2 \%$-diabetics). $25.1 \%$ of RRT patients had functioning kidney graft ( $\mathrm{n}=$ $461), 5.6 \%$ were treated by peritoneal dialysis $(n=103) .77 \%$ of HD patients were treated in hospital and $23 \%$ in 5 private dialysis centers (4 owned by Fresenius Medical Care). 37.3\% of HD patients were treated by convective methods (increase from $26.9 \%$ in 2005), mainly on-line hemodiafiltration. Ultrapure dialysis fluid was used in $76.4 \%$ patients. Median weekly time on HD-13.5 hours, median dry body weight $67 \mathrm{~kg}$, mean blood flow $284 \pm 44 \mathrm{ml} / \mathrm{min}$, single-needle HD$8.5 \%$ patients. Low molecular weight heparin- $18.5 \%$ patients, in the rest unfractioned heparin, median dose of 5500 units per HD. Vascular access on Dec 31, 2006 were: native AV fistula in 84.3\% prevalent and $74 \%$ incident HD patients, PTFE graft in $4.7 \%$ prevalent and $4 \%$ incident patients and HD catheter in $11 \%$ prevalent and $22 \%$ incident patients. The majority of AV fistula and graft (re)constructions, surgical salvage and Doppler of vascular access were performed by dedicated nephrologists. Epoetin therapy was prescribed in $89.3 \%$ of HD patients, median dose 6000 units per week, intravenously. Conclusions: The majority (77\%) of Slovenian hemodialysis patients are treated in hospital centers, $37 \%$ by convective methods (mainly on-line HDF), $76 \%$ with ultrapure dialysis fluid, with median weekly time on hemodialysis 13.5 hours. Vascular access for $84 \%$ prevalent and $74 \%$ incident hemodialysis patients is native $\mathrm{AV}$ fistula, usually constructed by dedicated nephrologists.

\section{P25 \\ Optimizing Correction of Renal Anemia in Chronic Hemodialysis Patients}

G. Reinecke, G. von Gersdorff (presenting), T. Benzing, C. Barth, and C.A. Baldamus

Clinic IV for Internal Medicine, University of Cologne, Cologne, Germany and KfH Kuratorium für Dialyse und Nierentransplantation e.V., Neu-Isenburg, Germany

Objectives: Optimized management of anemia in chronic hemodialysis patients (DP) needs to meet both the targets of medical guidelines (hemoglobin $(\mathrm{Hb})$ between 11 and $12 \mathrm{~g} / \mathrm{dl}$ ) as well as of regulatory authorities $(<15 \%$ DPs per clinic with hemoglobin $(\mathrm{Hb})<10 \mathrm{~g} / \mathrm{dl})$. To identify potentials in optimizing correction of anemia two subgroups with low $(<1 \mathrm{~g} / \mathrm{dl}$ : LSD) and high $(>1,5 \mathrm{~g} / \mathrm{dl}$ : HSD) standard deviation of $\mathrm{Hb}$, respectively, from a cohort of 14657 DPs from 149 dialysis clinics were analyzed. Results: The average $\mathrm{Hb}$ in the total population was $11,65 \mathrm{~g} / \mathrm{dl}+/-1,26 \mathrm{SD}$. The mean dose of erythropoietin (EPO) was 5699 I.E./wk (76,44 I.E./kg/wk). Overall, 19,97 \% of DPs required no EPO. Dialysis clinics with LSD showed a mean $\mathrm{Hb}$ of $11,58 \mathrm{~g} / \mathrm{dl}$ vs. $11,61 \mathrm{~g} / \mathrm{dl}$ in HSD-clinics. The requirement of EPO in LSD-clinics was 5411 I.E./wk $(72,96$ I.E./kg/wk), significantly lower than in clinics with HSD (5812 I.E./wk; 78,11 I.E./kg/wk). The number of DPs without EPO-requirement was larger in the LSD subpopulation $(21,51 \%$ vs. $17,36 \%)$. Conclusion: In this large and well characterized population we could identify a subgroup of DPs with low standard deviation of $\mathrm{Hb}$. In addition to the established medical benefits in this population there is also the aspect of lower EPO-costs (higher rate of patients without EPO-requirement and lower dose of EPO) detectable. With comparable $\mathrm{Hb}$ and ultrafiltration the risk of cardiovascular complications concerning hemoconcentration decreases in DPs with LSD. Furthermore, the rate of failure to meet targets of guidelines is not increased.

\section{P26 \\ Serum Endogenous Erythropoietin Value Is the Marker of Mortality in Hemodialysis Patients with Chronic Heart Failure}

\author{
M. Moriishi (presenting), H. Kawanishi \\ Tsuchiya General Hospital, Hiroshima, Japan
}

Introduction: Recent large scale studies pointed out that the risk of cardiac mortality was increased the higher $\mathrm{Hb}$ value used by erythropoietin stimulating agent (ESA). However, these studies could not clear whether the $\mathrm{Hg}$ rise induced the cardiac failure or was the result of cardiac failure. We reported that the cardiac failure stimulated the produce of endogenous EPO (endEPO) in the hemodialysis (HD) patients (JASN1999). This study is investigated the relation between endEPO and cardiac failure on the HD patients. Methods: The 400 stable HD patients in the present were subjected and investigated the relation between $\mathrm{Hb}$ value, ejection fraction (EF\%) of echo cardiogram, BNP and ESA resistance index (ERI). The 90 stable HD patients followed 10 years were subjected and investigated the relation between mortality rate and EF\%, ANP, BNP, and endEPO value. Results: The BNP was found the significant correlation to $\mathrm{EF} \%$ but not $\mathrm{Hb}$ value. Although $\mathrm{EF} \%$ was found the negative correlation to $\mathrm{Hb}$ value, the group of $\mathrm{EF} \%<50 \%$ showed less ERI value than the group of $\mathrm{EF} \%>50 \%(\mathrm{p}<0.003)$. In the 90 patients followed 10 years, the significant correlation between the endEPO and ANP, and BNP were found in the groups of $\mathrm{EF} \%<50 \%$, but not $\mathrm{EF} \%>50 \%$. In the groups of quantile for $\mathrm{EF} \%(50 \%)$ and endEPO value $(50 \mathrm{u} / \mathrm{mL})$, although the group of $\mathrm{EF} \%>50 \%$ was good mortality rate irrespective of endEPO value (n:70, 10 year mortality rate $60 \%$ ), the group of $\mathrm{EF} \%<50 \%$ and endEPO $>50 \mathrm{u} / \mathrm{mL}(\mathrm{n}: 8)$ was resulted significant higher mortality rate (all cases died less than 4 years) than the group of $\mathrm{EF} \%<50 \%$ and endEPO $<50 \mathrm{u} / \mathrm{mL}$ (n:9). Conclusions: This study indicated that the cardiac failure patients was suggested the increase endEPO because of the higher $\mathrm{Hb}$ and lower ERI. Moreover, the group of higher endEPO with cardiac failure was indicated the higher mortality rate in the long-term follow studies. In conclusion, the increase of endEPO value was increased the risk of death in HD patients. Further studies are required to clear the mechanism of endEPO in HD conditions. 
P27

\section{Implications of High Interdialytic Weight Gain in Chronic Hemodialysis Patients G}

\author{
G. Reinecke, G. von Gersdorff (presenting), T. Benzing, C. \\ Barth, C.A. Baldamus \\ Clinic IV for Internal Medicine, University of Cologne, \\ Cologne, Germany, KfH Kuratorium für Dialyse und \\ Nierentransplantation e.V., Neu-Isenburg, Germany
}

Objectives: High Interdialytic Weight Gain (IDWG) has been associated with both increased mortality and better nutritional status. We analyzed parameters of dialysis quality and prognosis in Hemodialysis Patients (DP) of the QiN-population ( $\mathrm{n}=14014)$ with low $\mathrm{IDWG}<1 \%$ (LWG, $\mathrm{n}=4469$ ) and high $\mathrm{IDWG}>4 \%$ of dry weight (HWG, $\mathrm{n}=4475$ ), respectively. Results: Mean IDWG in the HWG group was 2,95 vs. $1,07 \mathrm{~kg}$ in the LWG group. HWG-DPs were younger, had a lower dry weight, were more likely male, and had a lower Karnowski-Index. More patients were diabetic in the HWG than in the LWG group. Kt/Vsp was significantly higher in HWGDPs (1.61 vs. 1.43). HWG needed more EPO (105,27 I.E./kg/w vs. $84,84$ I.E. $/ \mathrm{kg} / \mathrm{w})$ to achieve a comparable $\mathrm{Hb}(11,68 \mathrm{~g} / \mathrm{dl}$ vs. $11,65 \mathrm{~g} / \mathrm{dl}$ ). Pre-dialysis blood pressure was higher, the postdialysis blood pressure lower in the HWG group, at no difference in the average number of antihypertensives. Residual diuresis was significantly lower in HWG-DPs (383 vs. $841 \mathrm{ml} / \mathrm{d}$ ). BMI, serum albumin and cholesterol was lower in HWG-DPs. However, phosphate, calcium-phosphate-product, creatinine and nPCR were significantly increased. Hospital admission and mortality rates were elevated in the population of HWG. Conclusion: In agreement with other studies we found HWG to be associated with lower age, male gender and lower dry weight. In contrast, we could not show an association between diabetes mellitus and increased IDWG. Hospital admission and mortality rates were not decreased in HWG-DPs although the Kt/V achieved was higher. High IDWG may be a strong modifier of morbidity and mortality in DPs.

\section{P28 \\ Daily Hemodialysis during Successful Pregnancy in Women with End-Stage Renal Disease}

\section{A. Marn Pernat (presenting), R. Ponikvar, J. Buturovic \\ Department of Nephrology, University Medical Center Ljubljana, Slovenia}

Objectives: We report on three pregnancies in women receiving daily dialysis in our center between 1996-2008 that all resulted in surviving infants. Method: At the conception the mean age of patients was 25 years. Two women began hemodialysis at 15 and 25 weeks of gestation but one was already on chronic hemodialysis for 17 years. Two patients received acetate free biofiltration and the third one received bicarbonate hemodialysis. They were dialyzed for four hours six days per week. Anticoagulation with heparin was a standard method. The predialysis BUN was maintained between 4.9-9.9 mmol/1 and creatinine between 158-294 $\mu \mathrm{mol} / 1$ during the pregnancy. Two women had adequate urine volume of more than $1000 \mathrm{ml}$ per day. Dry body weight during pregnancy in the woman on chronic hemodialysis for 17 years was determined by physical examination and weekly ultrasound measurements of vena cava inferior diameter. Anemia was treated with recombinant human erythropoietin, intravenous iron supplementation and/or transfusion. Results: All deliveries occurred before term due to premature rupture of membranes, preeclampsia, and intrauterine growth restriction. The mean gestation age at delivery was 27 weeks, 31 weeks, 35 weeks and mean baby weight was $635 \mathrm{~g}, 1300 \mathrm{~g}, 2150 \mathrm{~g}$, respectively. One baby went excellent. The other two infants experienced temporary respiratory distress syndrome but had no long-term medical problems. Conclusion: All three pregnancies in patients undergoing aggressive regimen of hemodialysis that were observed in our center were successful. We believe that early initiation of intensive daily hemodialysis even at a higher level of residual renal function may contribute to improvement of fetal outcome. Ultrasound measurement of vena cava inferior diameter can help to adjust optimal body weight during pregnancy.

\section{P29 \\ Regional Citrate Anticoagulation for Predilutional On-Line Hemofiltration in Intensive-Care Units}

\author{
J. Gubenšek (presenting), N. Škofic, R. Ponikvar, J. \\ Buturovic'-Ponikvar \\ Dept. of Nephrology, University Medical Center Ljubljana, \\ Ljubljana, Slovenia
}

Aim: To report our experience with regional citrate anticoagulation for intermittent predilutional on-line hemofiltration (HF) in patients with acute renal failure (ARF) in intensive-care unit (ICU). Patients and Methods: 41 patients with active bleeding or high bleeding risk were included in this retrospective analysis. Patients (30 male, 11 female) were $69 \pm 10$ years old. 94 HF procedures were performed using Gambro AK-200 Ultra S monitors with individual reverse osmosis preparing infusate on-line $(1.25 \mathrm{mmol} / 1$ calcium, $28 \mathrm{mmol} / \mathrm{l}$ bicarbonate, sodium and potassium as required). Regional citrate anticoagulation was achived using $4 \%(0.136 \mathrm{~mol} / \mathrm{l})$ trisodium citrate infused at the arterial line (starting at $400 \mathrm{ml} / \mathrm{h}$ ), $1 \mathrm{~mol} / 1 \mathrm{cal}-$ cium chloride infused at the venous line (starting at $7 \mathrm{ml} / \mathrm{h}$ ). Anticoagulation was assessed in a subgroup using 5-"no clotting" to 1-"total occlusion" score at arterial, venous bubble trap and dialyzer. Results: Duration of HF was $4 \mathrm{~h} 50 \mathrm{~min} \pm 47 \mathrm{~min}$, infusate volume reached was $77 \pm 9$ 1. Dual-lumen (26/41) or two single-lumen catheters $(15 / 41)$ were used for vascular access, blood flow was $267 \pm 31 \mathrm{ml} / \mathrm{min}$. Citrate infusion rate was $411 \pm 59 \mathrm{ml} / \mathrm{h}$ and calcium $7.4 \pm 1.2 \mathrm{ml} / \mathrm{h}$. None of the circuits clotted. Anticoagulation was assessed in 36/94 procedures, mean scores were 4.6 $\pm 0.6,4.2 \pm 1.0$ and $4.2 \pm 0.9$ at arterial bubble trap, dialyzer and venous bubble trap respectively. During the procedure there was a significant increase in ionized calcium $(1.01 \pm 0.14$ vs. $1.13 \pm 0.09 \mathrm{mmol} / 1, \mathrm{p}<0.001)$, sodium $(141 \pm 5$ vs. $143 \pm 3 \mathrm{mmol} / \mathrm{l}, \mathrm{p}<0.001)$ and bicarbonate $(23 \pm 6$ vs. $25 \pm 4 \mathrm{mmol} / 1, \mathrm{p}<0.01, \mathrm{n}=29)$, while increase in $\mathrm{pH}$ was insignificant ( $7.35 \pm 0.14$ vs. $7.38 \pm 0.11 \mathrm{mmol} / 1, \mathrm{p}=0.11, \mathrm{n}=29)$. There were two cases $(2 / 29,7 \%)$ of metabolic alkalosis $(\mathrm{pH}>7.5)$. Conclusion: Predilutional on-line hemofiltration with regional 
citrate anticoagulation using standard, calcium containing infusate $(1.25 \mathrm{mmol} / \mathrm{l})$ can be safely performed with good anticoagulation and rare metabolic side effects.

\section{P30}

\section{Treatment of Acute Renal Failure in Elderly Patients}

\section{P. Kes (presenting), N. Bašic'-Jukic', B. Brunetta Gavranić}

Department of Dialysis, University Hospital Centre Zagreb, Zagreb, Croatia

Background: Elderly patients are at high risk of both ischaemic and toxic-induced acute kidney damage, resulting in high incidence of acute renal failure (ARF). In the present study, we compare incidence, etiology and outcome of patients with hospitaly acquired acute renal failure (HAARF) requiring renal replacement therapy (RRT) in different age groups. Methods: During the 1-year prospective study, 62.951 consecutive patients admitted to University Hospital Centre Zagreb were followed up for development of ARF requiring RRT. Patients were divided into two age categories: $\leq 64$ years, and $\geq 65$ years. Results: Seventy one patient developed HAARF requiring dialysis $(0.11 \%$ of all patients hospitalized during study period). First group comprised 29 patients $(40.9 \%$ of all HAARF patients; age $18-$ 64 years, average 45.8 years) and second comprised 42 patients (59.2\%; age 65-90 years, average 70.0 years). There was significantly higher incidence of arterial hypertension (31.0\% vs. $73.8 \%)$ and mild CRF (24.1\% vs. $47.6 \%)$ among elderly patients. However, incidence of diabetes mellitus (24.1\% vs. $38.1 \%)$ and days of hospitalization when RRT was started (17.4 vs. 16.8) did not differ significantly. The most common primary causes of HAARF included sepsis, ischaemia and nephrotoxic drugs. Other reasons included radiographic contrast media, obstruction and rhabdomyolysis. Elderly patients developed HAARF more often after surgical procedure (76.2\% vs. 58.6\%). There was no significant difference in survival rate (33.3\% elderly vs. $34.5 \%$ younger patients) or incidence of CRF among survivors ( $21.4 \%$ vs. $20.0 \%$ respectively). Conclusion: Elderly patients make large proportion of population with HAARF requiring RRT. They have similar perspective for survival and renal function recovery to younger patients. Despite the high mortality rate, advanced age should not be the limiting factor in treatment of patients with HAARF requiring RRT.

\section{P31}

Single Pass Albumin Dialysis (SPAD) with Fresenius Multifiltrate System for Treatment of Acute Liver Failure

\section{A. Griskevicius (presenting), J. Audzijoniene, A. Baublys \\ Vilnius University Hospital Santariskiu clinics. Therapeutic Apheresis Unit. Santariskiu, Vilnius, Lithuania}

Objectives: Over the past 15 years many liver support concepts have been developed and evaluated. One of them is single-pass albumin dialysis (SPAD). It is a simple method of albumin dialysis using standard renal replacement therapy machines without an additional perfusion pump system: the patient's blood flows through a circuit with hemodiafilter. The other side of this membrane is cleansed with an albumin solution in counter-directional flow, which is discarded after passing the filter. Methods: From 2007 year seven SPAD procedures with Fresenius Multifiltrate system for three patients (1 females, age $40 \pm 5$ years) with acute liver failure were made. Levels of endogenous toxins (total bilirubin $[\mu \mathrm{mol} / 1]$, creatinine $[\mu \mathrm{mol} / 1]$ and ammonia $[\mu \mathrm{mol} / \mathrm{l}])$ and urea $[\mathrm{mmol} / \mathrm{l}])$ were monitored in blood sampled from venous line at the beginning and at the end of procedure. A $20 \%$ albumin solution was mixed with standard conventional dialysate to yield a dialysate with concentration of $5 \%$ albumin. We used dialysate flow rate $1-21 / \mathrm{h}$. Procedures was proceeded $3-5$ hours. Anticoagulation was performed with heparin. Blood was drawn from patients by using a central venous or a peripheral intravenous catheter. Results: A significant decrease of the serum level of total bilirubin was observed ( 1 patient $-208,8 ; 2$ patient $-109,9 ; 3$ patient $-115,8)$, ammonia (1-73,0;2-40,6; 3 - 52,3), creatinine $(1-351,7 ; 2-112,5 ; 3-128,6)$ and urea $(1-14,8 ; 2-9,7 ; 3-11,6)$. The reduction rate of total bilirubin 1 patient $-27,8 \%$; 2 patient $-35,0 \%$; 3 patient $-40,7 \%$; ammonia 1 patient $-52,7 \% ; 2-54,6 \% ; 3-44,1 \%$; creatinine $1-46,1 \%$; $2-63,6 \% ; 3-57,7 \%$ and urea $-1-22,5 \% ; 2-38,4 \% ; 3-34,1 \%$ respectively. Conclusion: Significantly improved serum levels of bilirubins, ammonia, creatinine and urea. There were no significant changes in hemoglobin and platelet levels. SPAD with Fresenius Multifiltrate system was uncomplicated and safe.

\section{P32}

\section{Treatment of Recurrent Focal Segmental Glomerulosclerosis with Plasma Exchange}

P. Kes (presenting), N. Bašic'-Jukic', V. Furic'-Čunko

Department of Dialysis, University Hospital Centre

Zagreb, Zagreb, Croatia

Focal segmental glomerulosclerosis (FSGS) may rapidly recur in transplanted kidney with consequent proteinuria and graft loss. Plasma exchange (PE) is often employed in the treatment of recurrent FSGS in renal transplant recipients. In the present study we report our experience in treatment of posttransplant FSGS. Patients were prospectively followed-up from the time of transplantation. Only patients with biopsy proven FSGS were included in investigation. From January 2002 to December 2007, 305 renal transplantations were performed, including 13 patients with FSGS. Five patients (38.4 $\%$ ) experienced disease recurrence 2 to 8 days after transplantation. Proteinuria ranged from 2.1 to $58 \mathrm{~g} /$ day (mean $16.6 \mathrm{~g} /$ day). PE was performed in all patients with recurrent disease, in 4 of them immediately after appearance of proteinuria. It was postponed in one patient because of the Staphylococcus Aureus sepsis, and was started 3 weeks after occurrence of proteinuria. He developed severe proteinuria exceeding $58 \mathrm{~g} /$ day which rapidly deteriorate kidney function and demanded graphtectomy. Among the patients who underwent PE, none of the patients achieved complete remission, while 2 of them achieved partial remission (proteinuria $1 \mathrm{~g}$ /day). Patients with partial remission experienced no recurrence during the $2.6+/-1.4$ years follow-up. All patients were included in the chronic program of PE 
which was performed every 2 to 3 weeks ( 5 to 29 procedures). After the failure of the chronic PE protocol, one male patient received 2 doses of rituximab, without significant effect on proteinuria. With the mean follow-up of 3.2 years, 3 out of 13 patients (23.07\%) lost their grafts, 2 because of the disease recurrence, and one because of the graft artery thrombosis. According to our experience, PE appears to be effective treatment of recurrent FSGS following renal transplantation, and should be started as soon as possible.

\section{P33}

\section{Changing Trend of Indications for Plasma Exchange during the Last Decades}

\author{
P. Kes (presenting), N. Bašic'-Jukic', B. Brunetta-Gavranić, \\ S. Glavaš-Boras, Z. Puretić \\ Department of Dialysis, University Hospital Centre \\ Zagreb, Zagreb, Croatia
}

Objectives: Results from randomized prospective trials have narrowed the spectrum of indications for use of plasma exchange (PE) on limited number of diseases. However, advances in the field of medical technology made possible wider clinical application of PE and generated several new indications. Methods: We analyzed retrospectively, and from 2002 followed-up prospectively, the database of Department of Dialysis, Zagreb University Hospital Center for indications for PE. Database included results of 6237 PE treatments performed on 634 patients from 1982-2007. Results: Number of patients subjected to PE has increased four times during the last 26 years (13,2 patients/year [pts/y] 1982-6 vs. 49,8 pt/y 2003-7) while average number of PE per patient has not changed significantly $(7,96$ $\mathrm{PE} / \mathrm{pt} / \mathrm{y} 1982-6$ vs. 6,84 PE/pt/y 2003-7). Largest increase in number of patients was noted in the field of neurological indications, which in the last 20 years made more than $50 \%$ of all patients subjected to $\mathrm{PE}$ (3,4 pt/y 1982-6 vs. 31,4 pt/y 2003-7). During the last 10 years, significant increase in number of patient with hematological indications (1,4 pt/y 1982-6 vs. 12,0 pt/y 2003-7) occurred as a consequence of increased number of hematopoietic cell transplantations and patients with thrombotic microangiopathies. During the last 5 years number of patients with nephrological indications increased (1,0 pt/y 1982-6 vs. $3,6 \mathrm{pt} / \mathrm{y} 2003-7)$, mostly due to increased number of kidney transplantations and its complications. Number of patients with dermatological (pemphigus) (1,0 pt/y $1982-6$ vs. 0 pt/y 2003-7) and immunological indications (4,0 pt/y 1982-6 vs. 0,4 pt/y 2003-7), significantly decreased due to development of new, more successful therapies, and lack of therapeutic effect of PE. Conclusions: Despite changes in indications for PE that have taken place, this procedure still has its applicability in various fields of medicine, whether traditional or newly created with development of medicine and technology.

\section{P34 \\ Renal Ultra-Filtration (UF) for Heart Failure (HF)}

\author{
D.S. Osabohien (presenting) \\ Ecc Global Concept Nigeria, Surelere, Nigeria
}

Objectives: Heart failure is responsible for more than 2,000,000 hospitalizations and 6,000,000 deaths yearly in Africa, as opposed to many other cardio vascular disorders, the annual incidence rate of heart failure, now estimated at 500,000 is increasing in Africa. The total cost of care yearly for chronic heart failure is high and cost up to 100 billion of US dollars. Therefore novel approaches are needed to improve patient outcome and reduce costs, the purpose of this study is to evaluate the safety and efficacy of isolated Ultra filtration in the management of patients with acutely decompensate chronic heart failure. Methods: These data are part of a prospective randomized case study of Ultra filtration as usual customary care for heart failure. The randomized patients had a pulmonary capillary wedge pressure while the therapy point was established and sustained also to under go the procedure continuous treatment with vocative compounds but not diuretics during this time. Results: Patients underwent ultra filtration the CI valves slightly decrease with time because of strongly dependent on the convective transport due to internal filtration. Target hemodynamic parameters were achieved with a mean net negative fluid and during the follow up periods CI did not change from the baseline. Conclusion: Ultra filtration is an effective and safe technique for the management of acutely decompensated heart failure. Heart failure internal filtration flow rate decreased with time.

\section{P35 \\ Solute Isolation Characteristics through On-Line HDF \\ Y. Tange (presenting), Y. Isakozawa, S. Takesawa, V. David \\ Kyushu University of Health and Welfare (Nobeoke, Japan)}

Objectives: To measure low molecular weight protein removal function under on-line hemodiafiltration (HDF) treatment. And compare solute removal with stokes radius. Method: Hemodialysis (HD) and on-line HDF were performed on 3 patients with polysulfone (PS) membrane dialyzers. The dialysis conditions were as follows: $250 \mathrm{~mL} / \mathrm{min}$ blood flow, $500 \mathrm{~mL} / \mathrm{min}$ dialysate flow rate which took 4 hours treatment. After 15 minutes of on-line HDF treatment, we started supplemental flow $12 \mathrm{~L} / \mathrm{h}$. After an interval of 60 minutes, we measured the clearance of $\beta_{2}$-microgloblin $\left(\beta_{2}-\mathrm{mg}\right)$, prolactin, and $\alpha_{1}$-microgloblin $\left(\alpha_{1}-\mathrm{mg}\right)$. We also sampled waste-line dialysate and measured the concentration of UN, $\beta_{2}-\mathrm{mg}, \alpha_{1}-\mathrm{mg}$, and albumin. Results: On-line HDF was superior in low molecular weight protein removal compared with HD. The UN was removed with diffusion, and $\alpha_{1}$-mg and albumin were removed with filtration. We understood that $\beta_{2}$-mg was affected by diffusion and filtration. Conclusion: Proteins of stokes radius over $3 \mathrm{~nm}$ like $\alpha_{1}$-mg and $3.5 \mathrm{~nm}$ like albumin contribute to membrane fouling. Yet, the isolation of proteins 
with over $3 \mathrm{~nm}$ stokes radius is difficult for HD and on-line HDF treatment with PS membrane. On-line HDF requires new technology for dialysis membrane such as selective adsorption of proteins.

\section{P36}

\section{A Trial on FLC Removal Using PMMA Membrane for Dialysis Patients}

W. Oshihara (presenting), H. Nagao, H. Megano, M. Koide, M. Takada, J. Arai

Toray Medical Co., Ltd., Tokyo, Japan,

Objectives: Free immunoglobulin light chains (FLCs) accumulate at high levels in the blood of dialysis patients and are likely to cause immunodeficiency during periods of dialysis. Our group examined the blood FLC concentration, $\kappa / \lambda$ ratio, and FLC removal in different dialysis modes using different dialysis membranes. Method: PMMA membrane (Toray BG-PQ, new type in Japan) under the HD condition was used for 7 chronic maintenance dialysis patients (at Medical Satellite Chita, Aichi, Japan) treated by HDF (5 PEPA, 2 Polysulfone) in a crossover fashion. FLCs in serum were measured using FREELITE ${ }^{\mathrm{TM}}$ Human Kappa Free Kit and Lambda Free Kit made with Binding Site, U.K. (purchased from Medical Biology Laboratories Co., Ltd. Japan). Each $\kappa$ type and $\lambda$ type FLC was quantitatively measured with a Dade Behring BNII ${ }^{\mathrm{TM}}$. Results: The $\kappa$ and $\lambda$ serum FLCs in HD patients $(\mathrm{n}=7)$ were $157.4+/-88.9 \mathrm{mg} / \mathrm{L}$ and $121.9+/-56.3 \mathrm{mg} / \mathrm{L}$, respectively, and were accumulated in concentrations 4 - to 16-fold higher than the concentrations in healthy controls $(65 \mathrm{mg} / \mathrm{L})(\mathrm{n}=15)$. The $\kappa / \lambda$ ratio was included in the standard range (0.26-1.65). In the HD cases dialyzed with PMMA (BGPQ) membrane, the FLCs were removed mainly by adsorption and the quantity of filtration to the whole dialysis waste fluid was very small. The ratio between the quantity of removal and Alb leakage $((\kappa+\lambda) /$ Alb) was higher in the PMMA HD group than in the HDF group, and the rate of $\kappa F L C$ removal was higher than the rate of $\lambda$ FLC removal. Conclusion: Though the FLCs were removed at high rates under the HDF condition, they were also effectively removed by adsorption with the PMMA membrane under the HD condition when albumin leakage was taken into account.

\section{P37 \\ Prevalence of Hepatitis C Virus Infection in Patients on Renal Replacement Therapy}

P. Dzekova (presenting) ${ }^{1}$, A. Asani ${ }^{1}$, G. Selim¹,

S. Pavleska1, L. Stamatov', S. Gelev', V. Amitov',

Lj. Stojkovski ${ }^{1}$, N. Ivanovski ${ }^{1}$, M. Polenakovic ${ }^{1,2}$, A. Sikole ${ }^{1}$

${ }^{1}$ University Clinic of Nephrology-Skopje; R. Macedonia,

${ }^{2}$ Macedonian Academy of Sciences and Arts, Skopje;

R. Macedonia

Hepatitis $\mathrm{C}$ virus (HCV) infection is a significant cause of morbidity and mortality in patients treated with hemodialysis or transplantation. Limited information is available on HCV infection in patients undergoing continuous ambulatory peritoneal dialysis (CAPD). The aim of the study was to evaluate the prevalence HCV infection among patients on renal replacement therapy (RRT). The evaluation of prevalence of HCV infection was made on 170 hemodialysis patients ( 105 men and 65 women, mean age $54.2 \mathrm{yr}$, and mean time on dialysis 100 months), 138 renal transplant recipients ( 87 men and 51 women, mean age $39.4 \mathrm{yr}$, and mean time after transplantation 40.3 months) and 24 CAPD patients (10 men and 14 women, mean age $44.7 \mathrm{yr}$, and mean time on CAPD 28.5 months). The presence of HCV antibodies, in the serum of patients, was determined by ELISA-III generation assay. The presence of HCV RNA in serum of HCV antibodies positive patients was assessed by reversetranscriptase PCR (Amplicor HCV Detection Kit, ver.2.0). HCV genotyping was performed by allele specific oligonucleotide (ASO) hybridization. Group comparison was made using the Student t-test, taking a $\mathrm{p}$ value of less than 0.05 to indicate statistical significance.The prevalence of HCV antibodies was $65.3 \%, 36.2 \%$, and $16.6 \%$ in hemodialysis patients, renal transplant recipients, and CAPD patients retrospectively. HCV positivity was significantly associated with the dialysis duration $(p=0.00)$, the serum levels of ALT $(p=-0.00)$ and AST $(p=0.00)$, but not with the number of transfused blood products in hemodialysis patients. HCV positivity was significantly associated only with the serum levels of AST ( $p=$ 0.00 ) in renal transplant recipients. The dominant genotype of $\mathrm{HCV}$ RNA was 1a in all patients on RRT. The high prevalence $(65.3 \%)$ of $\mathrm{HCV}$ infection, the homogeneity of the genotype, no presence of significant association between HCV positivity and number of blood transfusions, suggested a nosocomial transmission of $\mathrm{HCV}$ in hemodialysis patients. There is a high prevalence of HCV infection among renal transplant recipients $(36.2 \%)$, due to hemodialysis treatment before transplantation. The prevalence of HCV infection in CAPD patients is lower compared to other modalities of RRT, particularly dialysis, and it seems to be related to events that occurred prior to CAPD treatment.

\section{P38 \\ Quantitative Determination of Cutaneous Pigmentation in Patients with Chronic Renal Failure on Maintenance Hemodialysis - Analysis of Skin Lightness and Its Correlation with Various Uremic Molecules}

\author{
M. Shibata ${ }^{1}$ (presenting), H. Tawada', S. Taniguchi \\ ${ }^{1}$ Department of Hemodialysis, Koujukai Rehabilitation \\ Hospital, ${ }^{2}$ Department of Dermatology, Wakayama \\ Medical University, Kita-Nagoya, Japan
}

Background: Increased cutaneous pigmentation is an wellknown complication in patients with chronic renal failure on maintenance hemodialysis. However no detailed investigation has been documented probably because the complication is not seriously considered in the treatment of these patients. Method: 106 patients (M/F:72/34, mean age:63 \pm 12 years) on maintenance hemodialysis and 137 non-dialytic patients (M/F:80/57, mean age:58 \pm 26 years) were studied. Skin lightness was quantitatively determined using spectrophotometer, CR $-400^{\circledR}$ (Konica Minolta, Tokyo, Japan), in the 
abdominal area of the patients. Results and Discussion: Skin lightness was significantly reduced in hemodialytic patients $(\mathrm{p}<0.01)$, and correlated with the serum level of creatinine $(\mathrm{p}<0.01)$, although no significant relationships were observed between serum BUN and uric acid levels, and between KT/V value. Decreased skin lightness was also correlated with serum levels intact parathyroid hormone, $\alpha_{1}$ - and $\beta_{2}$ - microglobulins $(\mathrm{p}<0.05, \mathrm{p}<0.01, \mathrm{p}<0.05$, respectively). From these results, decreased skin lightness in hemodialytic patients is considered to originate from certain serum molecule(s) whose molecular weight(s) is(are) about $10^{4} \sim 3 \times 10^{4}$ biochemically. The reason why the decreased skin lightness correlates with serum level of creatinine, but not with that of BUN, is also discussed in the presentation.

\section{P39 \\ Beneficial Impact of Continuous Glucose Monitoring on Glycemic Control of Type 1 Diabetic Patients with Nephropathy}

\section{Radman (presenting), D. Ljutic' \\ Department of Internal Medicine, University Hospital Centre Split, Split, Croatia}

Objectives: Intensive insulin therapy is accompanied by considerable glycemic variation. We conducted an open-label clinical trial to investigate the usefulness of the real time continuous glucose monitoring system (GlucoDay) to assess glycemia and improve glycemic control in type 1 diabetic patients with nephropathy. Method: Real time continuous glucose monitors were inserted subcutaneously in 150 type 1 diabetic patients treated with intensive insulin therapy and selected into normoalbuminuric, microalbuminuric and macroalbuminuric group at the beginning and after 3 months. HbA1c, except GlucoDay data, were analyzed. Result: Initially, there were significant differences in HbA1c $(\mathrm{p}<0,05)$ between normo-, micro- and macroalbuminuric groups $(7,91 \pm 0,63 \% ; 8,38 \pm 0,58 \% ; 8,98 \pm 0,87 \%$; respectively). At endpoint for all groups, $\mathrm{HbAlc}$ levels decreased $(\mathrm{p}<0,05)(7,33 \pm 0,50 \% ; 7,84 \pm 0,52 \% ; 8,19 \pm 0,71 \%$; respectively); mean blood glucose levels based on continuous glucose monitoring decreased $\quad(p<0,0001) \quad(9,9 \pm 1,1 \mathrm{mmol} / 1 ; \quad 11,0 \pm 1,1 \mathrm{mmol} / 1$; $12,0 \pm 1,5 \mathrm{mmol} / 1$; respectively); median of time spent in the hypoglycemic range (glucose $<3,0 \mathrm{mmol} / \mathrm{l})$ decreased $(\mathrm{p}<0,05)\{4,2 \%$ $(0,0-15,2) ; 5,1 \%(1,1-14,0) ; 7,4 \%(1,3-18,4)$; respectively $\}$ and median of time spent in the hyperglycemic range (glucose $>8,0 \mathrm{mmol} / \mathrm{l})$ decreased $(\mathrm{p}<0,05)\{62,9 \%(31,4-92,6) ; 70,4 \%$ $(52,1-85,1) ; 70,9 \%(39,7-83,3)$; respectively $\}$. Conclusion: Real time continuous glucose monitoring system based on microdialysis has clinical benefits in patients with diabetic nephropathy due to important data can be obtained: glycaemic profiles, glycaemic fluctuations and efficacy of therapy. Further investigation is ongoing for final conclusion on purposefulness to use real time continuous glucose monitor for treatment of diabetes mellitus type 1 patients with end-stage renal disease.

\section{P40 \\ Actual State of the Dialysate Water Quality Evaluation in Japan - Endotoxin Measurement and Bacterial Count of Tap Water, RO and Dialysate}

Y. Isakozawa (presenting), Y. Tange, S. Takesawa, V. David

Kyushu University of Health and Welfare, Nobeoka, Japan

Objective: As dialysate water quality is reconsidered on ISO meeting, we reviewed actual level of the dialysate water endotoxin (ET) concentration and the cultivation of bacteria. Method: Tap water, RO water and dialysate of dialysis facility besides the patients on central supply system, which is widely used in Japan, were evaluated. After the sampling in tube with the ET stabilizer, concentration of ET was measured by LAL kinetic turbidimetric method. Also, bacteria count was done with agar plates of various culture media. Results: The ET concentration was as follows; 2 to $19,000 \mathrm{EU} / \mathrm{L}$ in tap water, ND $(=0.8)$ to $19 \mathrm{EU} / \mathrm{L}$ in $\mathrm{RO}$, and ND to $20 \mathrm{EU} / \mathrm{L}$ in dialysate. However, there are no correlations between the ET concentration and the bacterial count. Also, plate culture media show 0 to 20 $\mathrm{CFU} / \mathrm{mL}$ in the samples which have the ET concentration of less than detectable level. Conclusions: ET measurement requires only 2 hours and it is easy to feed back the results to the maintenance of the dialysis supply system. So, ET measurement is routinely done in dialysis centers in Japan. But our results suggest that we have to measure not only ET concentration but also bacterial count of dialysate water.

P41

\section{Removal of Biofilm on Dialysate Flow of the Central Supply System}

S. Takesawa (presenting), Y. Isakozawa, Y. Tange and V. David

Kyushu University of Health and Welfare, Nobeoka, Japan

Objective: To remove biofilm which forms on dialysate supply line, we conducted tests with discarded pipes. Method: Pipes used in this test of dialysate central supply were over 2 years with standard line maintenance contained $300 \mathrm{ppm}$ sodium hypochlorite and $0.5 \%$ acetic acid. Cut pipes were dipped for one week on a solution containing $12 \%$ sodium hypochlorite and $99 \%$ acetic acid as a beaker batch test. In addition, for over an hour, the solution was heated to around 60 degrees Celsius. After rinsing with RO water under scanning electron microscopy (SEM), all cut pipe samples were checked regarding their biofilm thickness. Results: SEM photographs clearly show biofilm formation on dialysate supply pipes over thickness of 30 micro-meters. Standard line maintenance has no effects on biofilm removal. Heated sodium hypochlorite poses no effect on biofilm thickness, but there was a slight effect on the heated acetic acid. Conclusion: Our conclusion showed that aseptic routine line maintenance in the central supply system is impossible. Absence of biofilm formation is the best way for regular line maintenance, and as such, it is strongly required to develop agents that avoid biofilm formation on the central supply dialysate system as currently used in Japan. 


\section{P42}

\section{Research of Water Quality Management at Hemodialysis Facility}

\section{F. Nakamura (presenting)}

Chiba Institute of Science, Choshi, Chiba, Japan

Objectives: Current research of water quality management at hemodialysis facility in Niigata prefecture, a regional in Japan, is conducted. Method: Screening of Et (Endotoxin) and bacteriological examination which was sampled from RO water, dialysate and hemodialysis device were conducted in July 2007. Results: In a case of water sampled from hemodialysis device, Et values obtained by 33 facilities was lower than $50 \mathrm{EU} / \mathrm{L}$ of standard value shown by Japanese Society for Dialysis Therapy. Viable cell counts using membrane filtration method of R2A-culture media ( 7 days) of 33 facilities was lower than $100 \mathrm{cfu} / \mathrm{ml}$ propounded by ISO/CD23500. Et values less than $1 \mathrm{EU} / \mathrm{L}$ and Viable cell counts less than $0.01 \mathrm{cfu} / \mathrm{ml}$ were obtained by 15 facilities simultaneously. Concentrations of $\beta$-glucan sampled from RO water, dialysate and hemodialysis device were 0.78 , 0.16 and $0.54 \mathrm{pg} / \mathrm{ml}$, respectively, and concentrations by all facilities were less than $20 \mathrm{pg} / \mathrm{ml}$ of positive. Concentrations of peptide glycan sampled from RO water at 2 facilities were 0.01 and $0.04 \mathrm{ng} / \mathrm{ml}$, and these were less than $0.6 \mathrm{ng} / \mathrm{ml}$ of positive. Peptide glycan sampled from dialysate and hemodialysis device was not detected at all facilities. Conclusion: Regarding as above research of Et, viable cell, $\beta$ glucan and peptide glycan, a good purification of water was confirmed in Niigata prefecture.

\section{P43}

\section{A PD System for Collection, Concentration with Hemodialyzer and Re-Instillation Might Eliminate Refractory Chylous Ascites}

\author{
N. Itami (presenting), J. Takada, H. Hamada, Y. Katsuki \\ Nikko Memorial Hospital, Kidney Center, Muroran, Japan
}

Introduction: Treatment of a patient with chylous ascites due to follicular lymphoma using a PD system is reported. Method: 1) PD catheter placed in abdomen connected to ascitic fluid collection bag. 2) Collected ascites circulated through Hemodialyzer (FB-07, Nipro, Japan), condensed with hemodialysis system and returned to abdomen using PD catheter. Case: 58-year-old female with abdominal pain and mass was diagnosed with follicular lymphoma. Abdominal distention and discomfort presented after 2 wks of chemotherapy. Abdominal aspiration showed chylous fluid with triglyceride $1767 \mathrm{mg} / \mathrm{dl}$ and sterile culture. Total parenteral nutrition and low-fat diet didn't improve conditions. She rejected surgical repair. Abdominal taps lowered serum albumin and worsened nutritional condition. Intravenous administration of hemofiltrated concentrated ascites was attempted but discontinued because patient became pale and hypotensive. Using our method, treatment reduced to 3-times/week. Ascitic drainage averaged $4 \mathrm{~L} /$ session. Condensing ascites 5-8 fold required $2.5 \mathrm{hrs}$ average. Hospital days/treatment days in 1st, 2nd, 3rd and 4th year was $73 \%$, $42 \%, 11 \%, 0 \%$. By year 6 , chylous ascites and treatment frequency decreased. With no accumulation at 6yrs.2months, the PD catheter was removed $2 \mathrm{mo}$. later. 74 months of treatment showed no incidence of peritonitis or adverse effects. Conclusion: Our method eliminated refractory chylous ascites and should be considered an alternative when surgical repair is ineffective.

\section{P44 \\ Effect of Icodextrin and Neutral Ph Dextrose Solution on Residual Renal Function in Peritoneal Dialysis Patients (Prospective, Multi-Center Study)

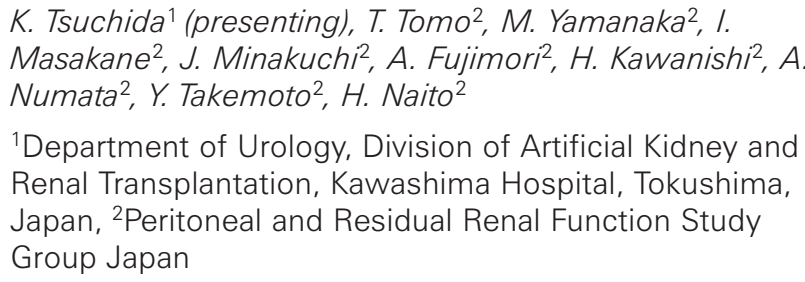

Objectives: Residual renal function (RRF) is an important factor of the well being of patients and affects mortality in peritoneal dialysis patients. Although use of icodextrin has several clinical benefits, its effect on RRF is sometimes reported. Furthermore, there are no reports for the effect of icodextrin on RRF in comparison with neutral $\mathrm{pH}$ dextrose solution (neutral-pH). The aim of this study was, therefore, to compare the change in RRF between patients treated with icodextrin or neutral-pH. Method: A total of 33 incident peritoneal dialysis patients with urine volume more than $500 \mathrm{~mL} /$ day were registered in this prospective, multi-center study (11 icodextrin group or 22 neutral-pH group). Patients were treated for 1.5-year either with icodextrin for their long dwell or with neutral-pH only. Laboratory data in the plasma and $24 \mathrm{~h}$-urine were collected at baseline and thereafter, every 6 months. Unpaired student's t-tests and Mann-Whitney U-tests were used when applicable to investigate differences between the two groups. Results: Baseline characteristics between the two groups were similar, except for height and urinary creatinine. The mean age was 64.2 (icodextrin group) and 64.9 years old (neutral-pH group). During follow-up, serum $\beta 2$-microgloblin concentration slightly increased in both groups, whereas other serum markers were not significantly different from those at the baseline. Urine volume and renal creatinine clearance similarly declined in both groups and the inter-group comparisons revealed no significant differences. Urinary protein excretion in icodextrin group tended lower compared to that in neutral-pH group, although the difference did not reach statistical significance. Conclusion: Our data suggest that RRF with icodextrin similarly declines, compared to that in patients treated only with neutral-pH during 24 months. 
P45

\section{The Epidemiology of Peritoneal-Dialysis- Related Peritonitis in Clinical Hospital Split, Croatia}

\author{
D. Ljutic' (presenting), M. Ćurkovic', J. Radic', V. Kovačić, \\ M. Radic', M. Šain, I. Jeličić \\ Department of nephrology and dialysis, Internal Clinic, \\ Clinical Hospital Split, Split, Croatia
}

Introduction: Continuous ambulatory peritoneal dialysis (CAPD) is important mode of renal replacement therapy in patients reaching end-stage renal disease. Peritoneal-dialysis-related peritonitis is the most frequent cause of morbidity and is among the leading causes of technique failure. Our objective was to assess some epidemiological and demographic aspects of peritoneal-dialysis-related peritonitis in population of uremic patients treated with CAPD in Clinical Hospital Split, Croatia. Methods: Subjects in this investigation were 112 (57 females and 55 males) out hospital patients of Dispensary for peritoneal dialysis of the Internal clinic of University Hospital Split, Croatia in period from 1999 to 2006 treated with CAPD. Average participant age was 58,35 $\pm 14,25$ (range 23-89) years. Mean dialysis treatment time was $4,22 \pm 2,28$ (range $1-9$ ) years. Results: There was at least one episode of acute peritonitis in 52 patients $(46,4 \%)$. Mean number of peritonitis episodes per subject was $1,03 \pm 1,65$ (range $0-11$ ). Among 52 subjects with peritonitis episode there were 31 male $(59,6 \%)$, and 21 female $(40,4 \%)$, this distribution was statistically significant $\left(\chi^{2}=4,289 ; \mathrm{p}=0,030\right)$. There was statistically significant positive correlation between time on dialysis treatment and number of peritonitis episodes $(r=0.47$, $\mathrm{p}<0.001)$. We could not find significant correlation between numbers of peritonitis and age $(r=0,088, p=0,17)$. Differences between the groups of subjects with peritonitis episodes and without peritonitis episodes are demonstrated as the Table 1.

Table 1. Differences between the groups of subjects with peritonitis episodes and without peritonitis episodes

\begin{tabular}{llll}
\hline & $\begin{array}{l}\text { Subjects with } \\
\text { peritonitis } \\
\text { episodes }\end{array}$ & $\begin{array}{l}\text { Subjects } \\
\text { without } \\
\text { peritonitis } \\
\text { episodes }\end{array}$ & $\begin{array}{l}\text { Significance } \\
\text { (p) }\end{array}$ \\
\hline $\begin{array}{l}\text { Age (years) } \\
\begin{array}{l}\text { Duration of } \\
\text { peritoneal } \\
\text { dialysis (years) }\end{array}\end{array}$ & $\begin{array}{l}57,75 \pm 15,69 \\
5,52 \pm 2,05\end{array}$ & $5,04 \pm 2,27$ & $<0,035$ \\
\hline
\end{tabular}

Conclusion: Peritoneal-dialysis-related peritonitis has relative high incidence among our CAPD-population, and 46,4\% of subject experienced at least one episode of peritonitis. We demonstrated male sex and duration of dialysis treatment as risk factors for peritonitis occurrence.

\section{P46 \\ Longer Survivor Preserved Body Protein Mass in Maintenance Hemodialysis Patients \\ J. Hikohiro (presenting), K. Okano, Y. Asamiya, N. Kimata, T. Iwasaki, K. Kikuchi, S. Otsubo, N. Miwa, J. Arai, M. Mineshima, K. Nitta, T. Akiba \\ Department of Blood Purification, Kidney Center, Tokyo Women's Medical University, Shinjyuku, Tokyo, Japan}

Objectives: Hemodialysis patients with a higher body mass index (BMI) have a lower risk of death, as shown by US and European observational studies. However, it was different from a clinical impression. The aim of this cross-sectional study was to compare changes in the body composition of patients by hemodialysis duration (vintage).

Method: 134 patients (M/F: $81 / 53$, mean age: $57.8 \pm 14.5$ years, mean HD duration: $16.1 \pm 10.0$ months) were divided into quintile by vintage. Total body protein and fat mass were measured by performing a multifrequency bioelectrical impedance analysis. Body weight, fat mass $(\mathrm{FM})$ and protein mass $(\mathrm{PM})$ were standarized by squared height $\left(\mathrm{m}^{2}\right)$, and expressed in $\mathrm{kg} / \mathrm{m}^{2}$ as BMI, FMI and PMI, respectively.

Results: Vintage were negatively correlated with BMI ( $\mathrm{r}=$ $-0.334, \mathrm{p}<0.001)$, FMI $(\mathrm{r}=-0.197, \mathrm{p}<0.001)$ and PMI $(\mathrm{r}=-0.246$, $\mathrm{p}<0.005$ ). Figure shows BMI within vintage quartiles, and table shows the body composition data. Compared to the Q1 group, the other longer vintage groups (Q2, Q3, Q4 and Q5) had significantly lower BMI, FMI and PMI. In contrast, Q2 to Q5 groups BMI, FMI and PMI were not statistically significant to each other groups. Additionally, these similar correlations were found when men and women were separately analyzed. Furthermore, longer survive BMI were decrease dependently.

Conclusions: The main findings from this study are that, (1) BMI, FMI and PMI were decrease in first few years, (2) After 5years or more longer vintage, these body compositions were stable. These results suggest that longer survivors have lower body composition, and maintained there protein mass and/or fat mass have importance. 


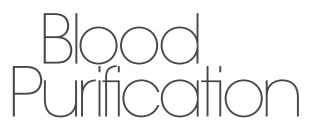

Adamlje, T. 443

Akiba, T. 436, 451

Akizawa, T. 431

Amitov, V. 437, 448

Arai, J. 448, 451

Arver, S. 435

Asamiya, Y. 451

Asani, A. 437, 448

Asci, G. 433, 438, 440

Audzijoniene, J. 446

Axelsson, J. 436

Bárány, P. 435, 436

Baldamus, C.A. 444, 445

Baldin, C. 439

Barth, C. 444, 445

Basci, A. 440

Bašić-Jukić, N. 437, 441, 446, 447

Baublys, A. 446

Beizai, M. 440

Benedik, M. 436

Benzing, T. 444, 445

Berta, M. 438

Berutti, S. 439

Bittinger, F. 432

Blanuša, D. 443

Borić Škaro, D. 442

Bozkurt, D. 440

Brunetta-Gavranić, B. 441, 446, 447

Bubić-Filipi, J. 441

Buturović-Ponikvar, J. 436, 443, 445

Buturovic, J. 445

Calabrese, G. 439

Carrero, J.J. 435, 436

Ceglar, Z. 436, 443

Černe, S. 443

Cimerman-Steklasa, S. 443

Čufer, A. 443

Ćurković, M. 451

David, V. 447, 449

Deambrogio, P. 439

Dikic, I. 434

Dinarello, C.A. 430
Drozg, A. 443

Duman, S. 438

Dzekova, P. 437, 448

Ekart, R. 443

Ezon, C. 440

Filipec Kanižaj, T. 441

Filipović, T. 442

Fuchs, S. 432

Fujimori, A. 450

Furić-Čunko, V. 446

Gelev, S. 437, 448

Germain, M. 432

Glavaš-Boras, S. 441, 447

Gonella, M. 439

Gracin, S. 441

Griskevicius, A. 446

Gubenšek, J. 445

Guček, A. 443

Gura, V. 440

Hamada, H. 450

Hayashi, K. 443

Heimbürger, O. 435, 436

Hermanns, M.I. 432

Hikohiro, J. 451

Hori, J. 443

Isakozawa, Y. 447, 449

Ishimaru, T. 443

Itami, N. 450

Ivanovski, N. 448

Iwasaki, T. 451

Iwashita, T. 443

Jacobson, S.H. 434

Jeličić, I. 442, 451

Jurić, I. 437

Kadlec, F. 438

Kadota, J. 443

Kandus, A. 436, 443

Kapun, S. 436, 443

Katsuki, Y. 450

Kawanishi, H. 444, 450

Kes, P. 435, 437, 441, 446, 447
Kikuchi, K. 451

Kimata, N. 436, 451

Kircelli, F. 438, 440

Kirkpatrick, C.J. 432

Knap, B. 436

Knotek, M. 441

Koide, M. 448

Kovačević-Vojtušek, I. 441

Kovačić, V. 442, 451

Kovač, J. 436

Kralj-Lopert, S. 443

Kralj, S. 443

Kunze, R. 442

Kužel, P. 438

Lindholm, B. 435, 436

Ljutić, D. 442, 449, 451

Lonnemann, G. 430

Lopot, F. 438

Möckel, M. 442

Malluche, H.H. 438

Malovrh, M. 436, 443

Marangoni, R. 441

Marn-Pernat, A. 436, 445

Masakane, I. 450

Matsuyama, K. 443

Matsuyama, M. 443

Mavrić, Ž. 435

Mazzotta, A. 439

Megano, H. 448

Mihovilović, K. 441

Minakuchi, J. 450

Mineshima, M. 451

Mitobe, M. 436

Miwa, N. 451

Močivn, M. 443

Monier, F.M.C. 438

Moriishi, M. 444

Mrakovčić-Šutić, I. 435

Mujais, S. 433

Murtagh, F.E.M. 432

Nagao, H. 448

Naito, H. 450

Nakagawa, M. 443

Nakamura, F. 450
Naumovski Mihalić, S. 441

Nehézová, K. 437

Nitta, K. 436, 451

Numata, A. 450

Ok, E. 438,440

Okabayashi, T. 443

Okano, K. 451

Osabohien, D.S. 447

Oshihara, W. 448

Oshikawa, K. 436

Otsubo, K. 436

Otsubo, O. 436

Otsubo, S. 436, 451

Ozaki, M. 443

Ozkahya, M. 438, 440

Panzetta, G. 431

Parini, P. 435

Pavleska, S. 437, 448

Pehar, G. 442

Polakovič, V. 438

Polaschegg, H.D. 439

Polenakovic, M. 448

Ponikvar, R. 436, 445

Portová, M. 437

Premru, V. 436

Puretić, Z. 441, 447

Quaglio, I. 439

Qureshi, A.R. 435, 436

Rački, S. 435

Radić, J. 442, 451

Radić, M. 451

Radman, M. 449

Reinecke, G. 444, 445

Reischig, T. 439

Remeš, O. 437

Richtrova, P. 439

Rindi, S. 439

Rulcova, K. 439

Rychlík, I. 437

Saksida, S. 436

Sanders, P.W. 433

Schindler, R. 442

Selim, G. 437, 448

\section{KARGER}

(C) 2008 S. Karger AG, Basel

Fax +4161306 1234

E-Mail karger@karger.ch

www.karger.com

Accessible online at:

www.karger.com/bpu 
Sevinc, E. 438, 440

Shaldon, S. 440

Sheriff, A. 442

Shibata, M. 448

Sikole, A. 437, 448

Šain, M. 442, 451

Škofic, N. 445

Stamatov, L. 437, 448

Stenvinkel, P. 435, 436

Stojcev, N. 437

Stojkovski, L. 448

Sugimoto, H. 436
Takada, J. 450

Takada, M. 448

Takemoto, Y. 450

Takesawa, S. 447, 449

Tange, Y. 447, 449

Taniguchi, S. 448

Tawada, H. 448

Titze, J. 430

Tomo, T. 443, 450

Toz, H. 438

Tsuchida, K. 450
Uchida, K. 436

Ueda, S. 436

Unger, R.E. 432

Vagelli, G. 439

Varl, J. 436

Verešová, J. 437

Vogt, B. 442

von Gersdorff, G. 444, 445

Vujičić, B. 435
Wilhelm, V. 442

Yamanaka, M. 450

Yilmaz, M. 438, 440

Yufu, K. 443

Zaputović, L. 435 